\title{
Perspectives on AFVs: State and City Government Fleet Manager Survey
}

\author{
M. Whalen, T. Coburn, and L. Eudy
}

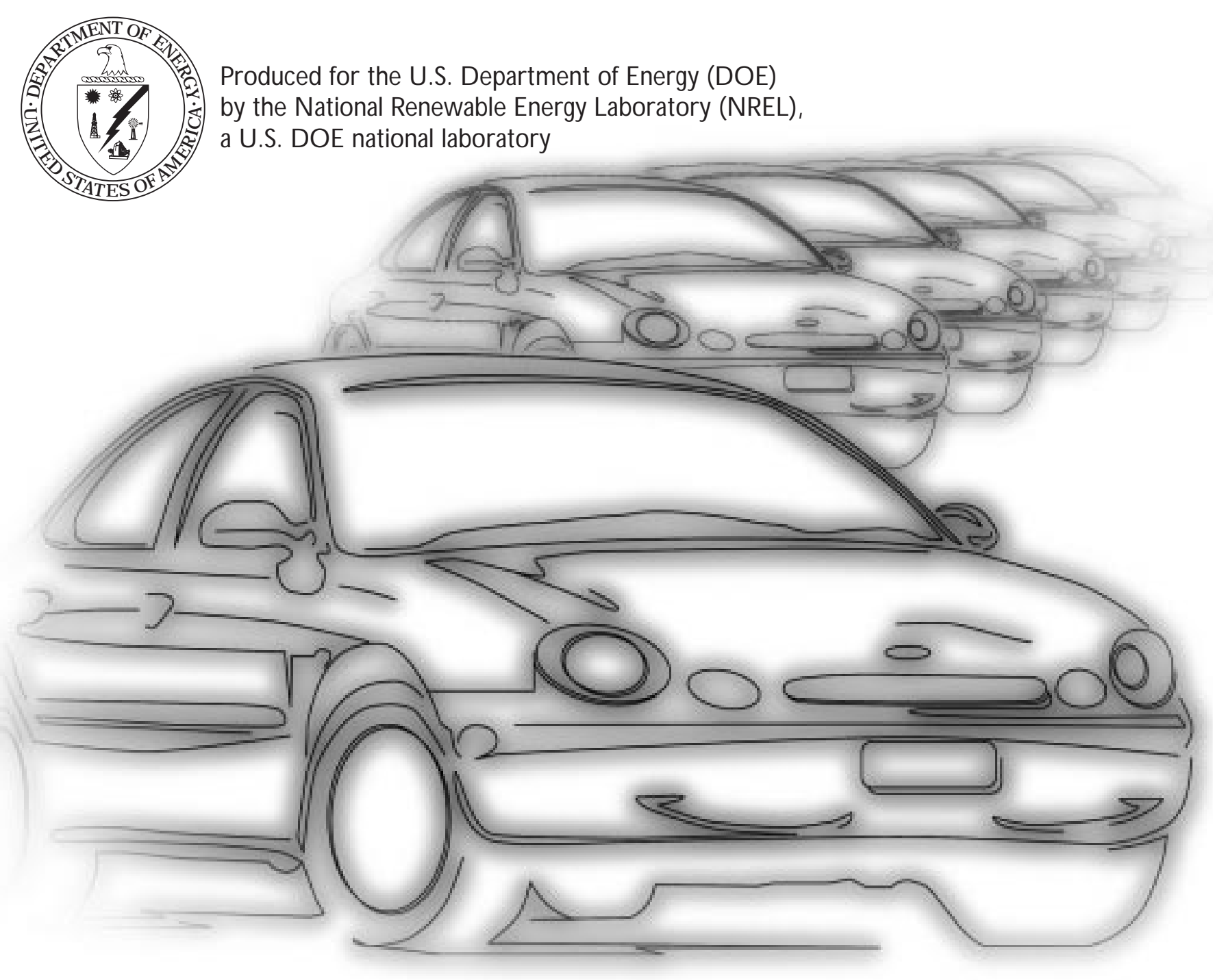




\title{
Perspectives on AFVs: State and City Government Fleet Manager Survey
}

\author{
M. Whalen, T. Coburn, and L. Eudy
}

Produced for the U.S. Department of Energy (DOE)

by the National Renewable Energy Laboratory (N REL),

a U.S. DOE national laboratory

DOE N ational Alternative Fuels Hotline: 1-800-423-1D O E World Wide Web: http://www.afdc.doe.gov

February 1999

N REL/T P-540-23980 


\section{Table of C ontents}

List of Tables $\ldots \ldots \ldots \ldots \ldots \ldots \ldots \ldots \ldots \ldots \ldots \ldots \ldots \ldots \ldots \ldots \ldots$

List of Figures $\ldots \ldots \ldots \ldots \ldots \ldots \ldots \ldots \ldots \ldots \ldots \ldots \ldots \ldots \ldots \ldots \ldots \ldots$

List of Tables and Figures - A ppendix A ............... iv

Executive Summary $\ldots \ldots \ldots \ldots \ldots \ldots \ldots \ldots \ldots \ldots \ldots$

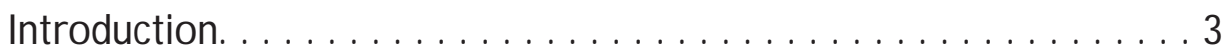

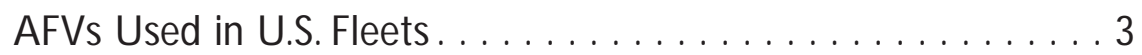

0 ther AFV Surveys ...................... 4

Survey $D$ evelopment, Implementation, and $D$ ata A nalysis. . . . . . . 5

Respondent and Fleet Characteristics $\ldots \ldots \ldots \ldots \ldots \ldots \ldots 7$

Results: Vehicle Use, Performance, and Acceptability . . . . . . . . . 12

Vehicle Assignment . . . . . . . . . . . . . . . . . . . . 12

D river Acceptability. . . . . . . . . . . . . . . . . . . 14

Alternative Fuel Availability . . . . . . . . . . . . . . 15

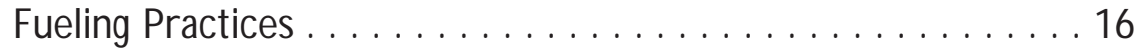

Vehicle Performance ........................ 17

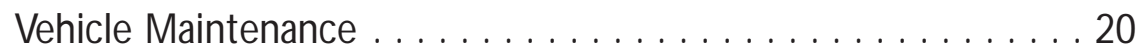

Vehicle 0 perational Costs. .................... 23

0 verall Satisfaction ......................... 24

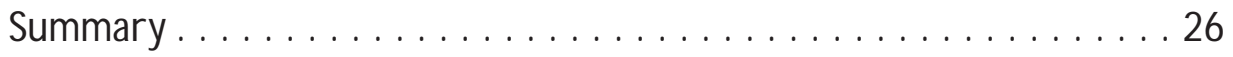

Acknowledgments $\ldots \ldots \ldots \ldots \ldots \ldots \ldots \ldots \ldots \ldots \ldots \ldots \ldots$

References............................... 28

A ppendix A: Results Summarized by Census Regions and City Types . . A-1 


\section{List of Tables}

Table 1. $\mathrm{N}$ umber of responses from state fleet managers by state and primary AFV type.................... 8

Table 2. $\mathrm{N}$ umber of responses from city fleet managers by city and primary AFV type $\ldots \ldots \ldots \ldots \ldots \ldots . \ldots$

Table 3. State fleet manager reports of specific performance-related complaints about AFVs, by primary AFV type in the fleet. . . 19

Table 4. City fleet manager reports of specific performance-related complaints about AFVs, by primary AFV type in the fleet. ... 19 


\section{List of Figures}

Figure 1. N umber of state and city fleet managers by primary AFV type in their fleets .......................... 7

Figure 2. Percentage distribution of respondents by primary AFV type in their fleets: (a) state fleet managers by census region and

(b) city fleet managers by city type. ............... 10

Figure 3. Fleet size distribution (number of vehicles per fleet) for all light-duty vehicles and AFVs. . .................. 11

Figure 4. Median sizes of fleets by primary AFV type in those fleets. . 12 Figure 5. Responses to "how are fleet vehicles assigned?"-

(a) all responses, state and city, (b) state responses by census . . region, (c) city responses by city type. . ............. 13

Figure 6. State fleet manager responses to "how acceptable are AFVs to drivers?" by fleet's primary AFV type ........... 14

Figure 7. City fleet manager responses to "how acceptable are AFVs to drivers?" by fleet's primary AFV type . . . . . . . . . 14

Figure 8. State fleet manager responses to "is there an alternative fuel station nearby?" by primary AFV type in fleet . . . . . . 15

Figure 9. City fleet manager responses to "is there an alternative fuel station nearby?" by primary AFV type in fleet . . . . . . . 15

Figure 10. Fleet manager responses about the type of fueling station used by the AFV fleet........................ 16

Figure 11. Fleet manager responses to "what fuel are your AFVs usually operated on?" - (a) state and (b) city, by primary AFV type in the fleet ................................. 17

Figure 12. Responses to "which vehicle type do you receive more complaints about?" . .................... 18

Figure 13. State fleet manager responses to "which vehicle type do you .. receive more complaints about?" by primary AFV type ..... 18

Figure 14. Responses to "do your AFVs require more or different scheduled maintenance than similar gasoline vehicles?" by primary AFV type in fleet - (a) state and (b) city fleet managers. ......... 21

Figure 15. Responses to "do your AFVs require more or different unscheduled maintenance than similar gasoline vehicles?" by primary AFV type - (a) state and (b) city fleet managers . . . . 22

Figure 16. Responses to "how do the costs of owning and operating AFVs compare to those of similar gasoline vehicles?" . . . . . 23

Figure 17. Fleet manager responses about overall satisfaction with AFVs in fleet - (a) all responses, state and city,

(b) state responses by primary AFV type,

(c) city responses by primary AFV type ............. 24

Figure 18. State fleet manager responses about overall satisfaction with AFVs in fleet by census region . .............. 25 


\section{List of Tables and Figures-Appendix A}

Table A-1. N umber of responses by state fleet managers by census ... region and primary AFV type.................. A-1

Table A-2. $\quad \mathrm{N}$ umber of responses by city fleet managers by city type (Clean Cities participants and other cities)............ A-1

Figure A-1. State fleet manager responses to "how acceptable are AFVs to drivers?" by census region ................. A-1

Figure A-2. City fleet manager responses to "how acceptable are AFVs to drivers?" by city type ................... A-1

Figure A-3. State fleet manager responses to "is there an alternative fuel station nearby?" by census region .............. A-2

Figure A-4. City fleet manager responses to "is there an alternative fuel station nearby?" by city type ............... A-2

Figure A-5. State fleet manager responses on type of refueling station ... used by fleet by census region . . ................

Figure A-6. City fleet manager responses on type of refueling station used by fleet by city type ................... A-3

Figure A-7. State fleet manager responses to "what fuel are your AFVs usually operated on?" by census region ......... A-3

Figure A-8. City fleet manager responses to "what fuel are your AFVs usually operated on?" by city type ............ A-3

Figure A-9. State fleet manager responses to "which vehicle type do you receive more complaints about?" by census region . A-4

Figure A-10. City fleet manager responses to "which vehicle type do you receive more complaints about?" by city type ... A-4

Figure A-11. State fleet manager responses to "do your AFVs require more or different scheduled maintenance than similar gasoline vehicles?" by census region. ................ A-4

Figure A-12. City fleet manager responses to "do your AFVs require more or different scheduled maintenance than similar gasoline vehicles?" by city type. .................. A-5

Figure A-13. State fleet manager responses to "do your AFVs require more or different unscheduled maintenance than similar gasoline vehicles?" by census region. .............. A-5

Figure A-14. City fleet manager responses to "do your AFVs require more or different unscheduled maintenance than similar gasoline vehicles?" by city type. ............... A-5

Figure A-15. State fleet manager responses to "how do the costs of owning and operating AFVs compare to those of similar gasoline vehicles?" by census region. ............... A-6

Figure A-16. City fleet manager responses to "how do the costs of owning and operating AFVs compare to those of similar gasoline vehicles?" by city type. ............... A-6

Figure A-17. City fleet manager responses about overall satisfaction with AFVs in fleet by city type ................ A-7 


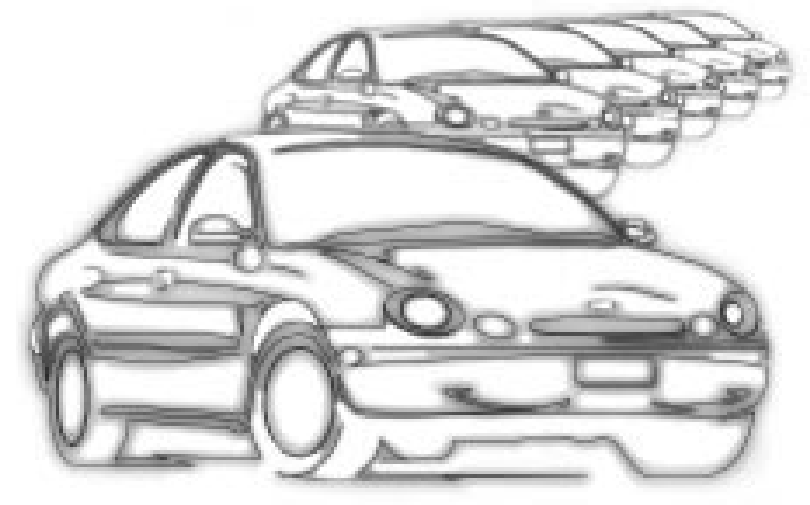

State and City Government Fleet Manager Survey

\section{Executive Summary}

For this survey, interviews were conducted with state government and local government fleet managers who are operating light-duty alternative fuel vehicles (AFVs) in their fleets. Through a series of questions, the survey collected information about vehicle use and acceptability, fuel avai lability, fuel use, and vehicle performance In all, data from 300 state government (all 50 states), and 287 local government ( 44 selected cities) fleet managers were collected and analyzed. Data were collected from fleets operating original equipment manufacturer vehicles fuel ed by compressed natural gas (CNG), ethanol (E85), methanol (M85), and electricity, and aftermarket conversion vehicles fueled by CNG and liquefied petroleum gas (LPG).

The survey results indicated that aftermarket conversions (CNG-fueled or LPG-fueled) were the most common primary AFV type in both the state and city government fleets. This was followed by ethanol flexiblefuel vehicles, again in both fleet manager groups. Fuel flexibility, as evidenced by the numbers of bi-fuel and flexiblefuel vehicles in these fleets, may be a factor in AFV selection for many of these fleets. Most of these state and city fleet managers reported having 10 or fewer AFVs in their fleets, and AFVs typically represented less than $6.5 \%$ of the light-duty vehicles in the fleets.

For the most part, these fleet managers assign their AFVs to individuals or groups, just like their gasoline vehicles. In both the state and city results, most fleet managers said their drivers do not have a preference for or against using AFVs. Among fleet managers who indicated their drivers do not want to drive AFVs, the most common reason cited was limited fuel availability.

Despite the concern about fuel availability, most of the fleet managers reported that al ternative fuel is available reasonably near their fleet location. Among the different alternative fuel types, M85 appears to be the least available alternative fuel. More than half of the state and city fleet managers reported that their AFVs are most commonly refuel ed at public service stations.

Fuel availability does not necessarily translate to a high percentage of alternative fuel use in cases where drivers have a vehicle that can use either alternative fuel or gasoline However, among the fleet managers whose primary AFV type was bi-fuel or flexiblefuel, the majority indicated that their AFVs are operated $50 \%$ or more of the time on the alternative fuel. 
Distributions of responses about reports of performancerelated complaints, maintenance, operating costs, and overall satisfaction indicate that the AFVs being operated in these fleets compare reasonably well to their gasoline vehicles. There were some differences in the distributions of responses to performance- related queries by AFV type Of note, the aftermarket conversions (CNG and LPG) received most of the fleet managers' reports of performancerelated complaints and received the most reports of overall dissatisfaction.

The survey results indicate that both state and city government fleets are using the available AFV types in their fleet applications. Although there are fuel availability issues in some places and some vehicle performance issues associated with using the different types of AFVs, the AFVs generally appear to be meeting the needs of these state and city government fleets. 


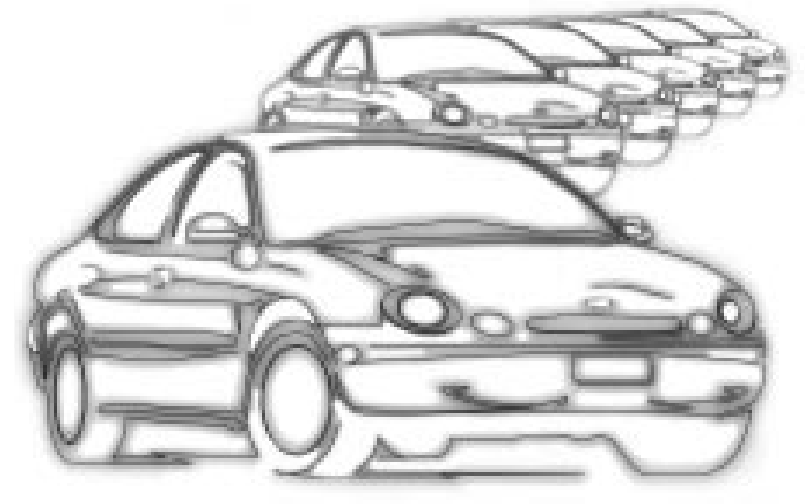

State and City Government Fleet Manager Survey

\section{Introduction}

In an effort to reduce national dependence on imported oil and to improve urban air quality, the U.S. Department of Energy (DOE) is promoting the development and deployment of alternative fuels and alternative fuel vehicles (AFVs). To support this activity, DOE has directed the National Renewable Energy Laboratory (NREL) to devel op and conduct projects to eval uate the performance and acceptability of light-duty AFVs compared to similar gasoline vehicles. As part of this effort, NREL has undertaken a number of evaluation projects, including conducting surveys with fleet managers and drivers of AFVs in state government fleets and local government fleets.

For this survey report, fleet managers from state and local government were interviewed as a follow up to the previous surveys conducted with fleet managers and drivers operating AFVs in federal government fleets. The results from the federal fleet surveys have been summarized and reported previously (Whalen and Coburn, 1997). The surveys were developed to collect information on fuel use, fuel availability, vehide performance, maintenance, and acceptability from the perspective of both drivers and fleets. This report summarizes the results of the survey.

\section{AFVs U sed in U.S. Fleets}

Currently, under the Energy Policy Act (EPAct), state government and fuel providers are mandated to include a certain percentage of AFVs in their new vehicle purchases. In $1998,50 \%$ of federal and $25 \%$ of state fleet vehicle purchases were required to be AFVs. In addition, $70 \%$ of fuel provider fleet vehicle purchases in covered areas were required to be AFVs. The current mandates do not include municipal and private fleets, but many of these fleets are voluntarily seeking to include AFVs in their fleets in anticipation of future requirements, or as part of local efforts to improve air quality. There are estimated to be more than 400,000 AFVs operating in fleets across the United States (Energy Information Administration [EIA], 1997). Of these AFVs, it is estimated that more than 328,000 are light-duty vehicles (LDVs). The LDV dlassification includes sedans, pickup trucks, and some passenger/ cargo vans, and is generally applied to a vehicle with a gross vehicle weight up to 8,500 pounds. Nearly, 75,000 of these light-duty AFVs are being operated in state and local government fleets, and an additional 230,000 are being operated in private fleets. These vehicles are located throughout the country and are used in a variety of different applications. 
The AFVs in the light-duty fleets can be grouped by the alternative fuel used: compressed natural gas (CNG), liquefied petroleum gas (LPG, often referred to as propane), methanol (M85), ethanol (E85), and electricity (ELEC). CNG vehicles can be any of three different types-dedicated original equipment manufacturer (OEM) models, which run only on CNG;

aftermarket conversions, which can be dedicated or bi-fuel; and bi-fuel OEM models. The bi-fuel vehides can run on either CNG or gasoline, but not on both at the same time LPG vehides include both aftermarket conversions (the vast majority of LPG vehicles) and a limited number of bi-fuel OEM vehicles. As with CNG vehicles, bi-fuel LPG vehides can be operated on LPG or gasoline, but not at the same time The ethanol and methanol vehides are flexible-fuel models from the OEMs. Flexible-fuel means the vehicles can operate on any combination of the alternative fuel and gasoline, up to a blend of $85 \%$ alternative fuel and $15 \%$ gasoline or $100 \%$ gasoline The electric vehicle category indudes both OEM vehides and gasoline vehides converted to operate on electricity.

According to EIA estimates (EIA, 1997), LPG vehides are the most numerous AFV types used in state/local government and private fleets-estimated to represent $60 \%$ and $77 \%$ of AFVs, respectively, in these fleets. The next most common AFV type is a CNG-fueled vehicle, estimated to be $22 \%$ of state/ local government fleet AFVs. E85, M85, and electric vehides each represent less than $10 \%$ of the AFVs in these fleets.

\section{0 ther AFV Surveys}

Other AFV-related surveys have been conducted in recent years, each with differing objectives and approaches. DOE's ElA has conducted several surveys to collect information on AFVs and al ternative fuel use (EIA 1996, 1997). The ElA surveys focused on estimating the numbers and types of AFVs in use, the consumption of alternative fuel, and the number and types of AFVs available. EIA relied heavily on secondary sources for much of its data, induding government agencies (federal, state, and local), AFV manufacturers, and energy suppliers.

In 1996, a survey was conducted with federal fleet managers who were operating AFVs (Whalen and Coburn, 1997). This survey was designed to collect information from fleet managers about in-service AFVs in federal fleets. It also sought some comparative information from fleet managers about similar gasoline vehides in their fleets. The current survey is very similar, but the target population includes state and local government fleet managers. 


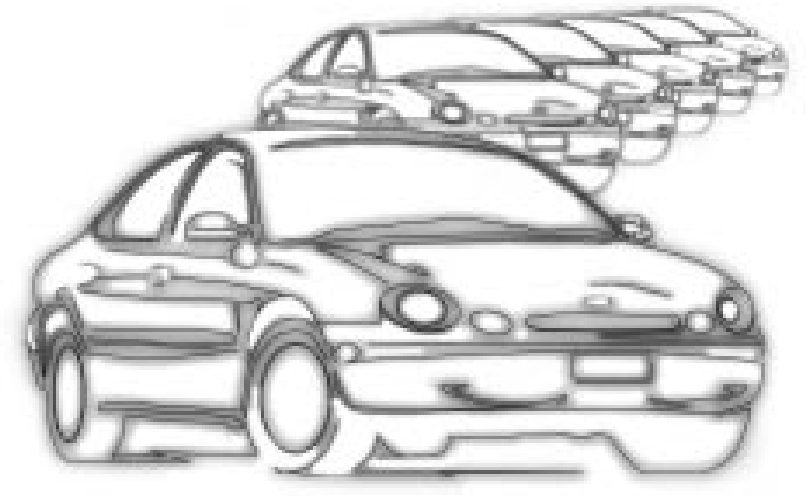

State and City Government Fleet Manager Survey

\section{Survey D evelopment, Implementation, and Data Analysis}

State and city fleet managers were sel ected as the target population for this survey, which is a follow-up to the previous survey with the U.S. federal fleet. As with the federal fleet survey, the population of state and city fleet managers is functionally and geographically diverse, with no single comprehensive list of names available Therefore, a detailed contact list of appropriate stateand local government fleet managers had to be constructed, drawing on several different sources, including the National Fleet Vehicle database and the American Business Institute's white pages. The development of the contact list included identifying fleet managers in all 50 states (for the state government survey), and in 48 selected cities (for the local government survey). In all, a list of more than 4,500 fleet managers was developed, induding state and local government contads. Fleet managers were randomly selected from the contadt list, with some effort made to choose participants in areas where al ternative fuels were known to be available No attempt was made to stratify the sample in advance according to AFV type, model, make or manufacturer of vehide, although such information was collected from each respondent.

After evaluation of survey resources and population, a target sample size of 250 state fleet managers and 288 local government fleet managers was established. The goal was to complete interviews with five fleet managers in each state and to complete interviews with six fleet managers in each city. In total, 617 fleet managers (state and city) were interviewed from the list of 4,549 contacts, yiel ding an overall sampling rate of $13.6 \%$. The fleet managers interviewed induded 303 state government and 314 local government fleet managers. The desired number of interviews was exceeded in several states and cities, and at least five interviews were completed in each state The interviewers left messages when they were not able to directly contact fleet managers, and would proceed to make other contacts. Many of the fleet managers called back, and the interviewers would conduct the interview(s) even if they had reached their quota for that state or city. Some problems were encountered in trying to complete the desired number of interviews in four of the originally selected cities. These cities were replaced with other comparablesized cities, and the goal of completing six interviews in each selected city was reached.

On evaluation of both complete data sets, a number of responses were eliminated from the detailed data analysis. Some reasons for excluding responses included the primary AFV type identified was not a light-duty vehicle, the response was from a city which was replaced, or the response was from outside the designated coverage area for the city. In all, data from 300 state government (all 50 states), and 287 local government (44 of the selected cities) responses were included in the detailed analysis.

The 300 state fleet managers and 287 city fleet managers interviewed reported operating 25,628 AFVs (combined total, with 17,500 in the state fleets and 
8,128 in thecity fleets) in their fleets. This total represents $34 \%$ of all the light-duty AFVs $(74,820)$ estimated by theEIA (1997) to have been operated by state and dity government organizations during 1996. Along with the sampling rates of $11.8 \%$ for the statefleet managers, and $14.3 \%$ for the city fleet managers, this information points to a highly representative sample on which to base survey condusions.

The sample size in this survey is sufficient to maintain an overall margin of error of approximately $4 \%$ at $95 \%$ confidence. For the two subgroups, state fleet managers and city fleet managers, the margins of error are estimated to be $6 \%$ and $5 \%$, respectively, at $95 \%$ confidence The margins of error associated with percentages or proportions of other subgroups of the population may be higher, due to smaller effective sample sizes.

NREL personnel developed the survey questionnaire, which induded questions about AFV acceptability, fuel use, and subjective vehicle performance. The survey included the same questions asked of federal fleet managers during an earlier survey (Whalen and Coburn, 1997), in addition to several new questions. The new questions sought additional feedback on fuel stations, vehicle maintenance, overall satisfaction, and costs of operating AFVs. The survey was conducted from October through early December 1997.

Thestaff of Petroleum Information-Dwights, a subcontractor to NREL, conducted the interviews using conventional telephone interviewing techniques. All survey responses were recorded on individual survey forms, and tabulated for subsequent anal ysis. There was essentiall ly a 100\% response rate in this survey, in that every subject responded to at least part of the interview. Such a high degree of success is attributable to the fleet managers' interest in AFVs. State fleets are required to indude a certain percentage of AFVs in their new light-duty vehide purchases Many state fleets have used AFVs in their fleets for some time, so many of them are acaustomed to being questioned about their AFVs. Many cities arelooking to AFVs as part of addressing local air quality issues, or in anticipation of potential mandates

The general approach to the analysis of the survey data involved use of crosstabulations and contingency tables, with survey data subdivided into appropriate groupings Descriptivestatistics (such as means, percentages, and standard deviations) werealso compiled. Formal tests of statistical significancewere performed to assess differences between categories and groups, where appropriate Some of the results of such tests are reported (usually in the form of Chi-square statistics and associated probabilities) in appropriate sections of this report. All data analyses were conducted using the JMP statistical software from the SAS Institute

The principal grouping involved subdivision by primary AFV type operated by each fleet The state government data was al so anal yzed and compared by census region (Northeast, Midwest, South, and West) to determine if any regional differences in responses would be revealed. In addition, the local government data were analyzed according to whether the city/area is a participant in the DOE's Clean Cities Program. Clean Cities is a locally based government/ industry partnership coordinated by DOE, and focused on expanding use of alternatives to gasoline and diesel fuel. No target numbers by AFV type were established in advance, because we wanted to ascertain which of the AFV types are being most commonly operated in fleets across the country. 


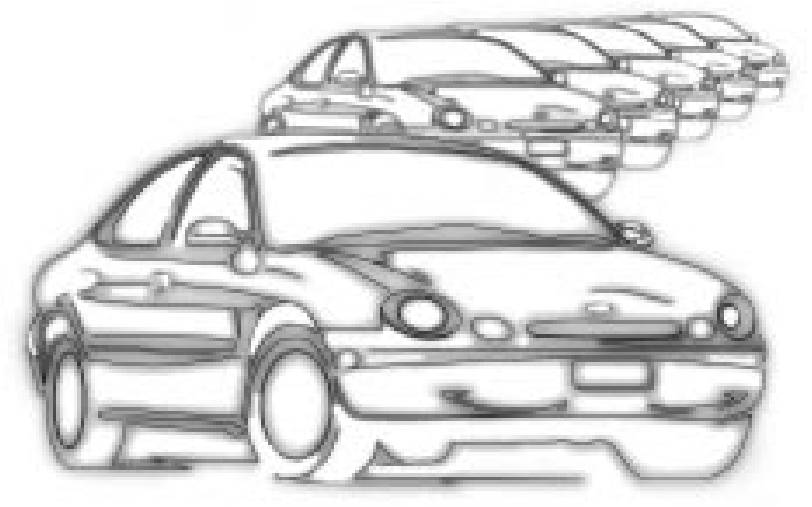

State and City Government Fleet Manager Survey

\section{Respondent and Fleet Characteristics}

As discussed in the previous section, the results from 300 state government and 287 local government interviews were included in the detailed data analysis. The number of interviews conducted in each state and city are summarized in Table 1 and Table 2. At least five interviews were completed in each state, with a maximum of 11 completed with fleet managers in lowa. The final analysis included responses from 44 different cities, each with at least 6 interviews completed.

The cities were selected to geographically represent the country, and to include different size cities. Of the selected cities, 50\% (22 of 44) were designated as, or were participants in, city or regional Clean Cities programs as of September 30, 1997. The city sizes are defined by population as follows: large, greater than 500,000 people; medium, from 200,000 to 500,000 people; and small, less than 200,000 people The survey encompassed 14 large cities, 16 medium cities, and 14 small cities, equally divided between Clean Cities and other cities.

During the interview process, fleet managers were asked to identify the primary type of AFV in their fleets. Figure 1 shows the number of respondents whose primary AFV type was a CNG, E85, electric, M85, or LPG model. The responses about CNG models were further divided into aftermarket conversions (CNG-CON), and OEM dedicated (CNG-DED) or OEM bi-fuel (CNG-BI) vehides.

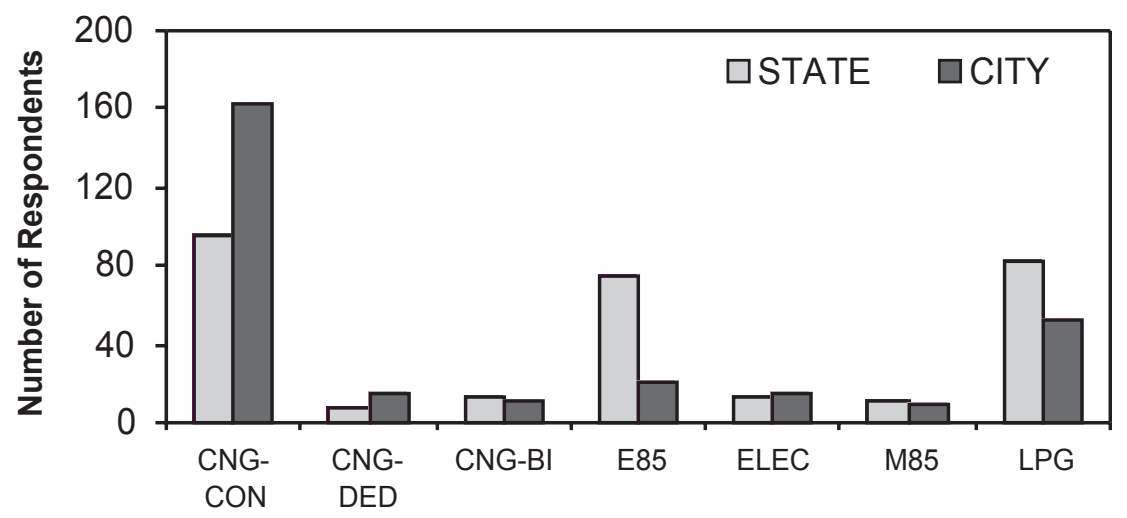

Primary AFV Type

Figure 1. Numbers of state and city fleet managers by primary AFV type in their fleets 
Perspectives on AFVs

\begin{tabular}{|c|c|c|c|c|c|c|c|c|}
\hline STATE & CNG-CON & CNG-DED & CNG-BI & E85 & ELEC & M85 & LPG & TOTAL \\
\hline AK & 4 & 1 & & & & & & 5 \\
\hline $\mathrm{AL}$ & 2 & & & 2 & & 1 & 2 & 7 \\
\hline AR & 5 & 1 & & & & & & 6 \\
\hline$A Z$ & 3 & & 1 & & & 1 & 1 & 6 \\
\hline CA & 1 & & & & 1 & 5 & 1 & 8 \\
\hline $\mathrm{CO}$ & 1 & 1 & 1 & & & & 3 & 6 \\
\hline CT & 3 & & & & & & 3 & 6 \\
\hline $\mathrm{DE}$ & 2 & & 1 & & & & 2 & 5 \\
\hline $\mathrm{FL}$ & & & & & 2 & & 4 & 6 \\
\hline GA & 4 & & & & & & 1 & 5 \\
\hline $\mathrm{HI}$ & & & & & 3 & & 2 & 5 \\
\hline $\mathrm{IA}$ & 1 & & & 1 & & & & 2 \\
\hline ID & 1 & & & 4 & & & & 5 \\
\hline IL & & & & 7 & & & & 7 \\
\hline IN & 2 & & & 3 & & & & 5 \\
\hline KS & 1 & & & 4 & & & & 5 \\
\hline $\mathrm{KY}$ & 1 & & & 4 & & & & 5 \\
\hline LA & 4 & & & & & & 1 & 5 \\
\hline MA & 2 & & & & & & 3 & 5 \\
\hline MD & 4 & & 4 & & & & 1 & 9 \\
\hline ME & & & & & & & 5 & 5 \\
\hline $\mathrm{Ml}$ & 3 & & & & & & 1 & 4 \\
\hline $\mathrm{MN}$ & & & & 5 & & & 1 & 6 \\
\hline MO & 4 & & & 4 & & & 2 & 10 \\
\hline MS & 3 & & & & & & 2 & 5 \\
\hline MT & & & & & & & 5 & 5 \\
\hline $\mathrm{NC}$ & & & & & 2 & & 7 & 9 \\
\hline ND & 1 & & & 6 & & & & 7 \\
\hline $\mathrm{NE}$ & 1 & & & 6 & & & & 7 \\
\hline $\mathrm{NH}$ & 1 & & & & & 1 & 3 & 5 \\
\hline NJ & 2 & 1 & & & & & 2 & 5 \\
\hline NM & & & & 1 & & & 9 & 10 \\
\hline NV & 4 & & 1 & & & & 1 & 6 \\
\hline NY & 2 & & & & & 1 & 2 & 5 \\
\hline $\mathrm{OH}$ & 1 & & & 3 & & & 1 & 5 \\
\hline OK & 3 & & 1 & 1 & & & & 5 \\
\hline OR & 3 & 2 & & & & & & 5 \\
\hline PA & 2 & & 2 & & & & 1 & 5 \\
\hline RI & 1 & 2 & 1 & & & & 1 & 5 \\
\hline SC & 1 & & & & 1 & & 4 & 6 \\
\hline SD & 1 & & & 5 & & & & 6 \\
\hline $\mathrm{TN}$ & & & & 3 & 1 & & 1 & 5 \\
\hline TX & 1 & & & & & & 5 & 6 \\
\hline UT & 6 & & & & & & & 6 \\
\hline VA & 2 & & 1 & & & & 2 & 5 \\
\hline VT & 1 & & & & 4 & & & 5 \\
\hline WA & 2 & & & 1 & & 2 & & 5 \\
\hline WI & 1 & & & 5 & & & 1 & 7 \\
\hline WV & 4 & & 1 & & & & 2 & 7 \\
\hline WY & 5 & & & & & & 1 & 6 \\
\hline TOTAL & 96 & 8 & 14 & 74 & 14 & 11 & 83 & 300 \\
\hline
\end{tabular}

Table 1. Number of responses from state fleet managers by state and primary AFV type 
Table 2. Number of responses from city fleet managers by city and primary AFV type

\begin{tabular}{|c|c|c|c|c|c|c|c|c|}
\hline CITY & CNG-CON & CNG-DED & $\overline{C N G-B I}$ & E85 & ELEC & M85 & LPG & TOTAL \\
\hline ALBUQUERQUE, NM & 7 & 1 & & & & & & 8 \\
\hline ANCHORAGE, AK & 1 & 1 & & & & & & 8 \\
\hline ATLANTA, GA & 4 & 2 & & & & & & 6 \\
\hline AUSTIN, TX & 1 & & & & & & 5 & 6 \\
\hline BALTIMORE, MD & 5 & & & & & & 1 & 6 \\
\hline BATON ROUGE, LA & 5 & & 1 & & & & & 6 \\
\hline BISMARK, ND & 5 & & & 1 & 1 & & & 7 \\
\hline BOSTON, MA & 6 & & & & & & & 6 \\
\hline BUFFALO, NY & 6 & & & & & & & 6 \\
\hline CARSON CITY, NV & 2 & & 1 & & & & 3 & 6 \\
\hline CHARLESTON, WV & 8 & & & & & & & 8 \\
\hline CHEYENNE, WY & 7 & & & & & & & 7 \\
\hline CHICAGO, IL & 1 & & & 4 & 1 & & & 6 \\
\hline COLUMBUS, $\mathrm{OH}$ & 6 & & & 1 & & & 1 & 8 \\
\hline DENVER, CO & 5 & & & & & & 3 & 8 \\
\hline HONOLULU, HI & & & & & & & 6 & 6 \\
\hline HOUSTON, TX & 4 & & 2 & & & & & 6 \\
\hline INDIANAPOLIS, IN & 4 & 1 & & 1 & & & 1 & 7 \\
\hline KANSAS CITY, MO & 4 & 2 & & & & & & 6 \\
\hline LANSING, MI & 6 & & & & & & & 6 \\
\hline LITTLE ROCK, AR & 3 & 2 & 1 & & & & & 6 \\
\hline LOS ANGELES, CA & 5 & & & & 1 & 4 & 1 & 11 \\
\hline MADISON, WI & 1 & & & 2 & & & 3 & 6 \\
\hline MEMPHIS, TN & 2 & & & 2 & & & 2 & 6 \\
\hline MISSOULA, MT & & & & & & & 6 & 6 \\
\hline NASHVILLE, TN & & & 1 & 3 & & 1 & 1 & 6 \\
\hline NORWICH, CT & 6 & & & & & & & 6 \\
\hline OAKLAND, CA & 2 & 2 & 2 & & 1 & & & 7 \\
\hline OKLAHOMA CITY, OK & 6 & & & & & & & 6 \\
\hline OMAHA, NE & 4 & & & & & & 2 & 6 \\
\hline PEORIA, IL & 6 & & & 2 & & & & 8 \\
\hline PHOENIX, AZ & 4 & & & & & 1 & 1 & 6 \\
\hline PORTLAND, ME & 2 & & & & 4 & & 1 & 7 \\
\hline PORTLAND, OR & 4 & & & & 1 & & 2 & 7 \\
\hline PROVO, UT & 6 & & & & & & & 6 \\
\hline RALEIGH, NC & 3 & & & & 1 & & 2 & 6 \\
\hline RICHMOND, VA & 5 & & 1 & & & & & 6 \\
\hline ROANOKE, VA & 1 & 1 & 1 & & & & 4 & 7 \\
\hline SACRAMENTO, CA & 2 & & & & & 4 & & 6 \\
\hline SAN ANTONIO, TX & & & & & & & 6 & 6 \\
\hline SEATTLE, WA & 5 & & & & & & 1 & 6 \\
\hline ST PAUL, MN & 1 & 1 & & 4 & & & 1 & 7 \\
\hline SYRACUSE, NY & 2 & 1 & 2 & & 1 & & & 6 \\
\hline TOLEDO, OH & 5 & 1 & & & & & & 6 \\
\hline TOTAL & 162 & 15 & 12 & 2 & 15 & 1 & 53 & 287 \\
\hline
\end{tabular}


Figure 2. Percentage distribution of respondents by primary AFV type in their fleets: (a) state fleet managers by census region and (b) city fleet managers by city type
One hundred eighteen state fleet managers (39.3\%) identified CNG models as the primary AFV type in their fleets, followed by $83(27.7 \%)$ identifying LPG models, 74 (24.7\%) identifying E85 models, 14 (4.7\%) indicating ELEC models, and 11 (3.7\%) M85 models. Among respondents with CNG models as their primary AFV type, fleets with aftermarket conversions predominated, with 96 of the total $118 \mathrm{CNG}$ responses.

When evaluated by census region (see Figure 2a), some differences in distribution of responses by primary AFV type can be seen. In the South and the West, CNG-fueled vehicles were the AFV type reported most often ( $46.7 \%$ and $47.4 \%$ of respondents, respectively). In the Northeast, the most commonly reported primary AFV type was evenly split between CNGand LPG-fueled AFVs (43.5\% each). Ethanol-fueled (E85) AFVs dominated the primary AFV types (72.5\%) reported by the state fleet managers in the Midwest.

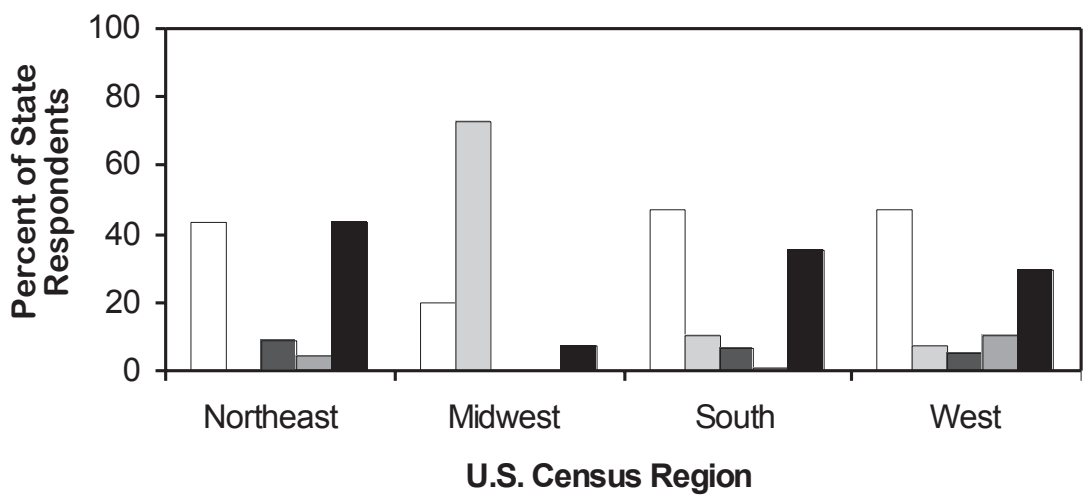

(a)

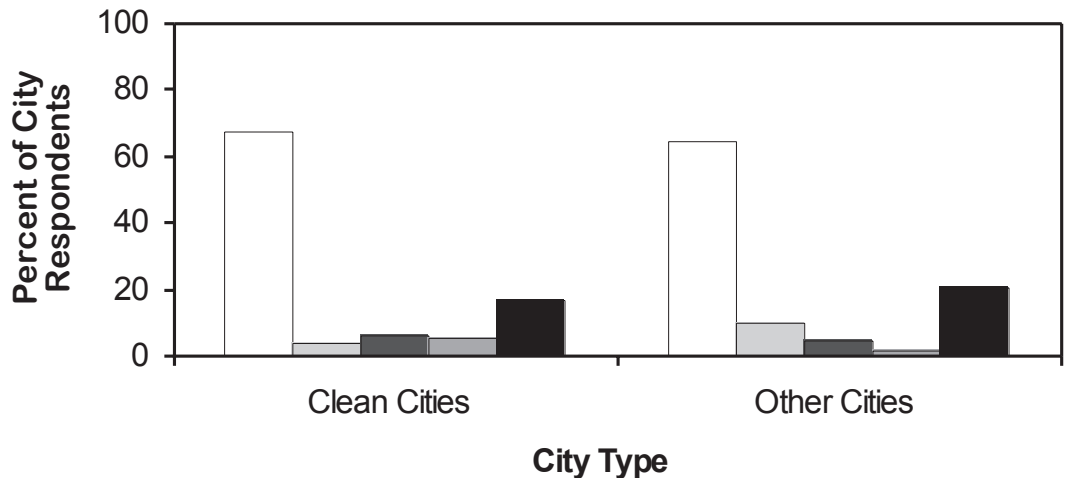

(b)

$\square$ allCNG $\square$ E85 $\square$ ELEC $\square$ M85 $\square$ LPG

Overall, the local government fleet manager responses about primary AFV type came out in the same order as that of the state fleet managers-CNG, LPG, E85, electric, and M85-but nearly 27\% more respondents indicated their primary AFV type was CNG-fueled (189 or $65.8 \%$ of respondents). This is followed by $18.5 \%$ indicating LPG models, $7.0 \%$ indicating E85 models, $5.2 \%$ responding electric models, and 3.5\% saying M85 models. When grouped by Clean Cities and other cities (see Figure 2b), there was 
little difference in the distribution of the primary AFV type identified by the responding fleet managers.

The fleets represented by the 300 state survey respondents contained a total of 274,509 light-duty vehicles (all types combined). In the case of the local government respondents, the fleets represented included a total of 167,031 light-duty vehides (all types combined).

Of particular interest are the numbers of AFVs contained in the fleets of the survey respondents. The responding state fleet managers reported having a total of 17,508 AFVs ( $6.4 \%$ of all vehicles) in their fleets. The city fleet mangers reported having a total of $8,128 \mathrm{AFVs}$ ( $4.9 \%$ of all vehicles) in their fleets. In a somewhat surprising finding, the total number of AFVs reported in designated Clean Cities was less than that reported in the other selected cities-2,884 AFVs ( $3.3 \%$ of all vehicles) compared to 5,244 AFVs ( $6.6 \%$ of all vehicles), respectively.

In eval uating the distribution of fleet sizes (see Figure 3), fleets containing 500 or more vehicles were most common for both the state and local fleets represented by the survey. Thirty-three percent of the state fleet managers and nearly $26 \%$ of the local government fleet managers reported fleet size at 500 or more vehicles. When eval uating the distribution of numbers of AFVs in the fleets, the results were quite different. Most state fleet managers ( 169 out of 300 , or $56.3 \%$ ) and city fleet managers ( 182 out of 287 , or $63.4 \%$ ) reported having 10 or fewer AFVs in their fleets.

The fleet sizes represented by the respondents varied widely from thousands of vehicles to only one or two vehicles. The overall median fleet size was determined to be 200 vehides for both the state and local government fleets. The median, or 50th percentile, is an average value that is not sensitive to wide numerical fluctuations. Figure 4 shows the median fleet sizes for total fleets and total AFVs, grouped by primary AFV types. For the state fleets, this figure indicates that fleets with CNG vehicles as their primary AFV type tend to be larger than fleets with other vehicles as their primary AFV type It also indicates that the median numbers of AFVs are small in comparison-less than 20 for the state fleets and less than 10 vehicles for city fleets.

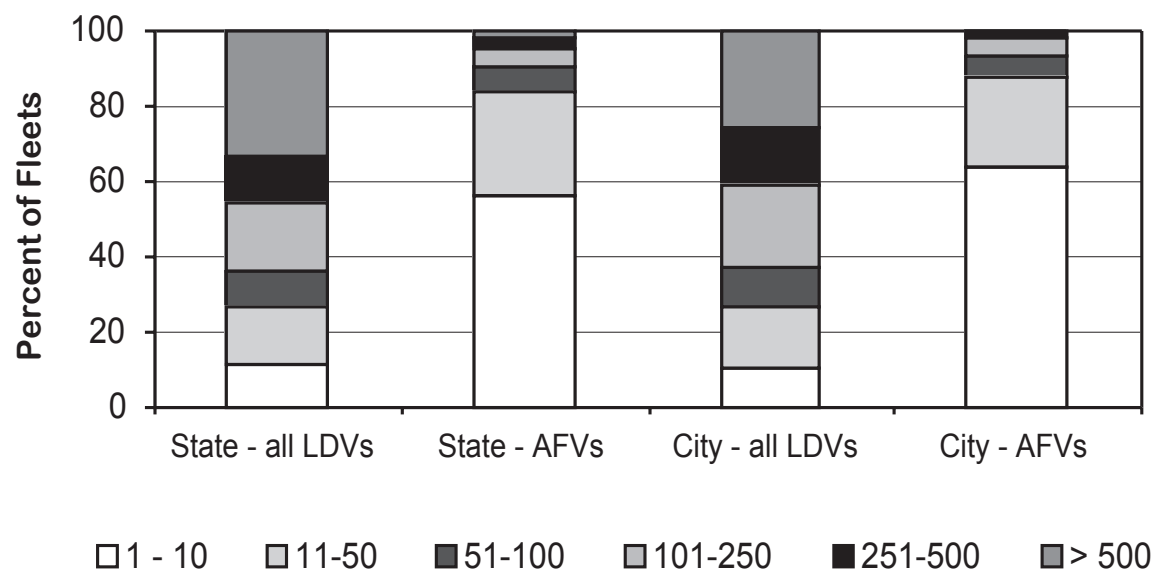

Figure 3. Fleet size distribution (number of vehicles per fleet) for all light-duty vehicles and AFVs 


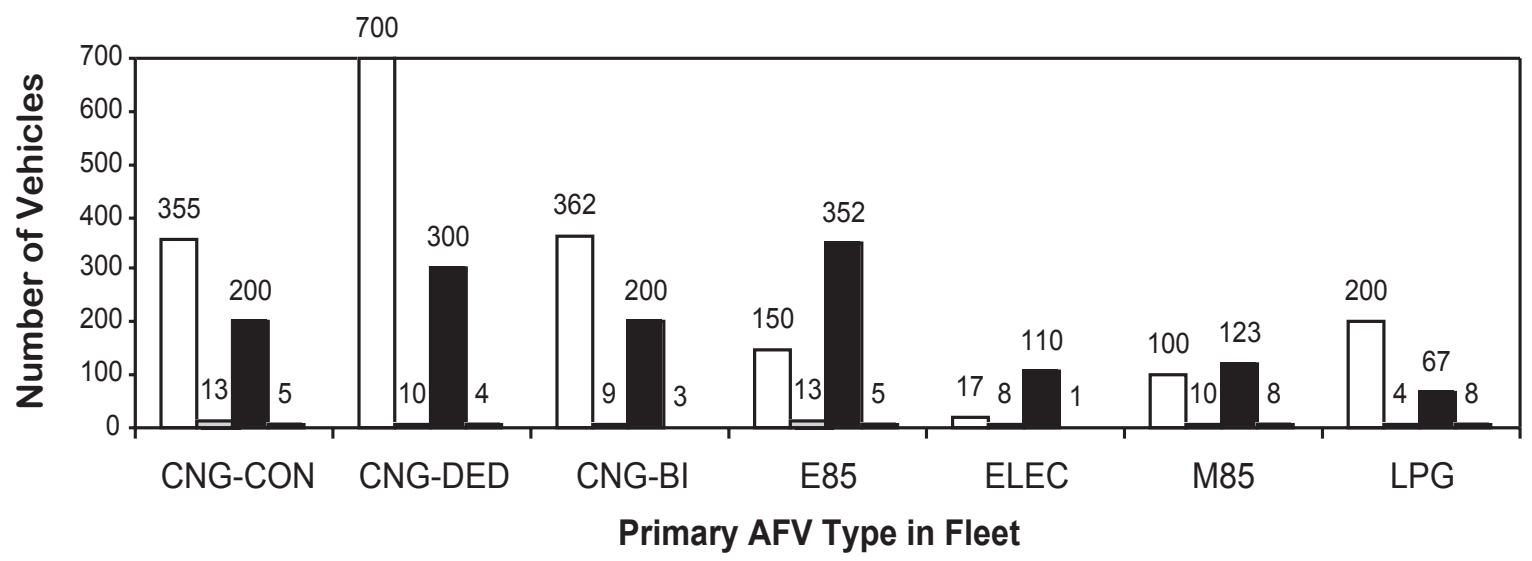

$\square$ State - entire fleet $\square$ State - AFVs $\quad$ City - entire fleet $\quad$ City - AFVs

Figure 4. Median sizes of fleets by primary AFV type in those fleets
Operation of more than one AFV type was reported by 65 out of 300 ( $21.7 \%)$ state fleet, and 41 out of 287 (14.3\%) local government fleets. This means their fleets include AFVs that operate on one of the other alternative fuels, besides the fuel of their primary AFV type.

\section{Results: Vehicle U se, Performance, and Acceptability}

The use and incorporation of AFVs into fleets has increased over the last several years, mostly as a result of mandates under EPAct. The survey results presented in the following sections provide information on the experiences of a number of state and local government fleet managers who are operating AFVs in their fleets. Most of the graphs and tabulations presented summarize all responses by fleet type-state or city government. Additional information is presented by region (state government response) or by city type (Clean Cities or other cities), where interesting differences were uncovered. (Other results pertaining to analyses by region or city type are included in Appendix A.)

\section{Vehicle Assignment}

Most survey participants ( $56 \%$ of state respondents and $54 \%$ of city respondents) reported that their fleet vehicles are assigned to a specific driver, as shown in Figure $5 a$. Only $16 \%$ of the state respondents and $9 \%$ of the city respondents indicated that the vehicles they manage are assigned to a vehicle pool. These results are quite different from those of the federal fleet survey, where the majority of respondents (67\%) indicated vehicles are assigned to a group or department. This implies that most of the vehides represented in this survey have only one driver, which may affect the types and amount of feedback the fleet managers receive about them.

A statistically significant difference $\left(\chi^{2}=20.1\right.$, d.f. $\left.=6, \alpha=0.02\right)$ in response to the question about vehide assignment was found when the state fleet manager responses were grouped by region (see Figure 5b). 


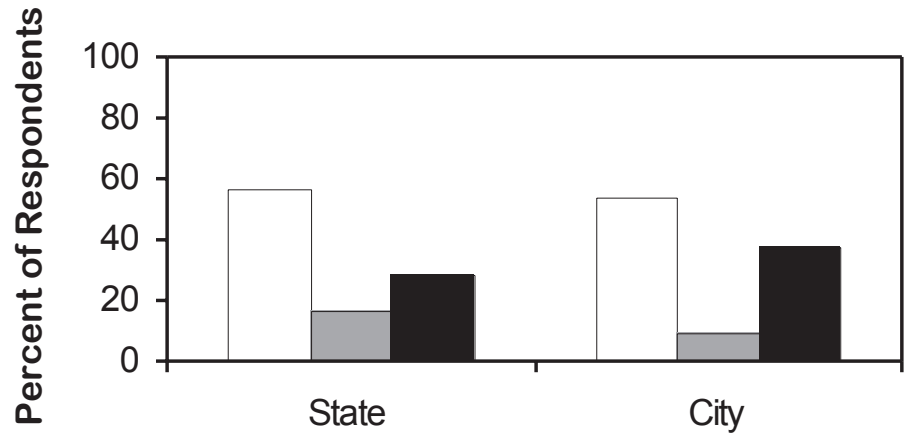

All AFV Types

(a)

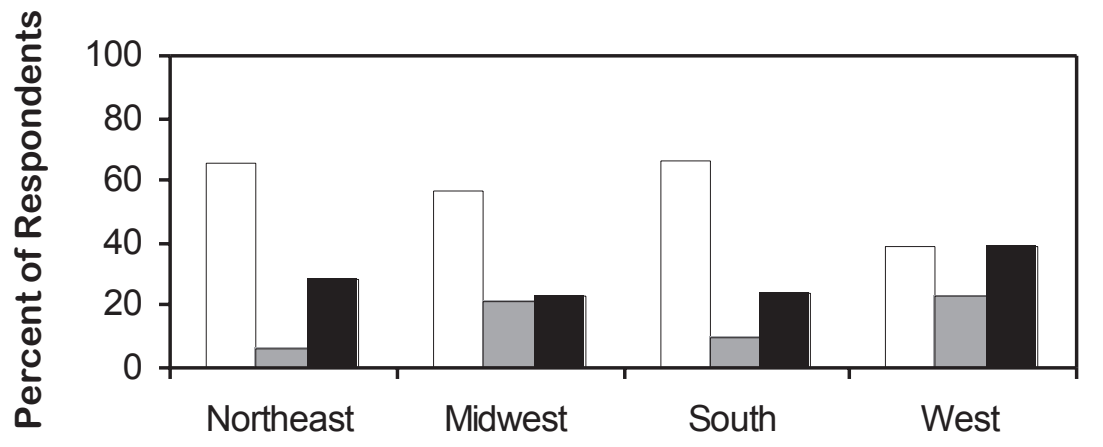

All AFV Types

(b)

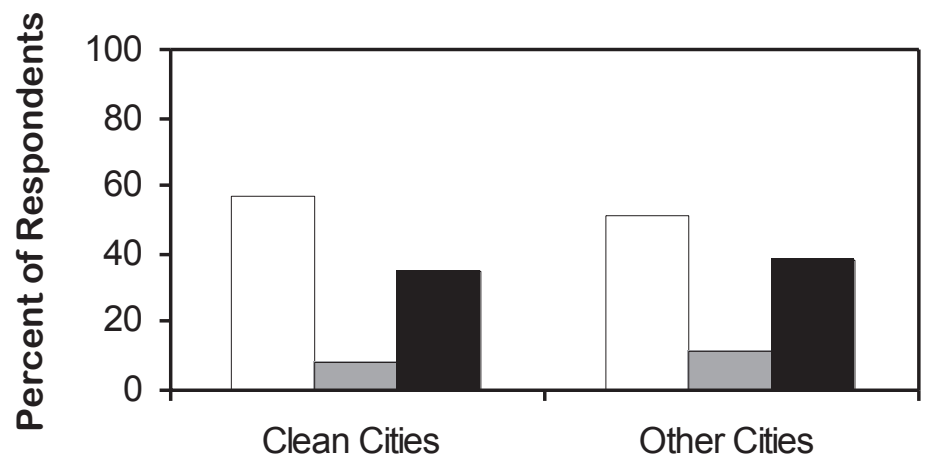

All AFV Types

(c)

Assigned to individual $\quad \square$ Pool vehicle $\quad$ Assigned to group

Fleets with vehides assigned to individual drivers are much less common in the West than in other regions (38.5\% compared to a range of 56\% to $66 \%$ in the other regions). When a similar comparison is done with the city responses grouped by Clean Cities and other selected cities ( see Figure 5c), no difference is seen in how vehicles are assigned. Again, vehicle assignment may influence the types and amounts of feedback fleet managers receive about their vehides and their subsequent survey responses, reported below.
Figure 5. Responses to "how are fleet vehicles assigned?" - (a) all responses, state and city, (b) state responses by census region, (c) city responses by

city type 


\section{D river Acceptability}

Figure 6. State fleet manager are AFVs to drivers?" by fleet's primary AFV type responses to "how acceptable

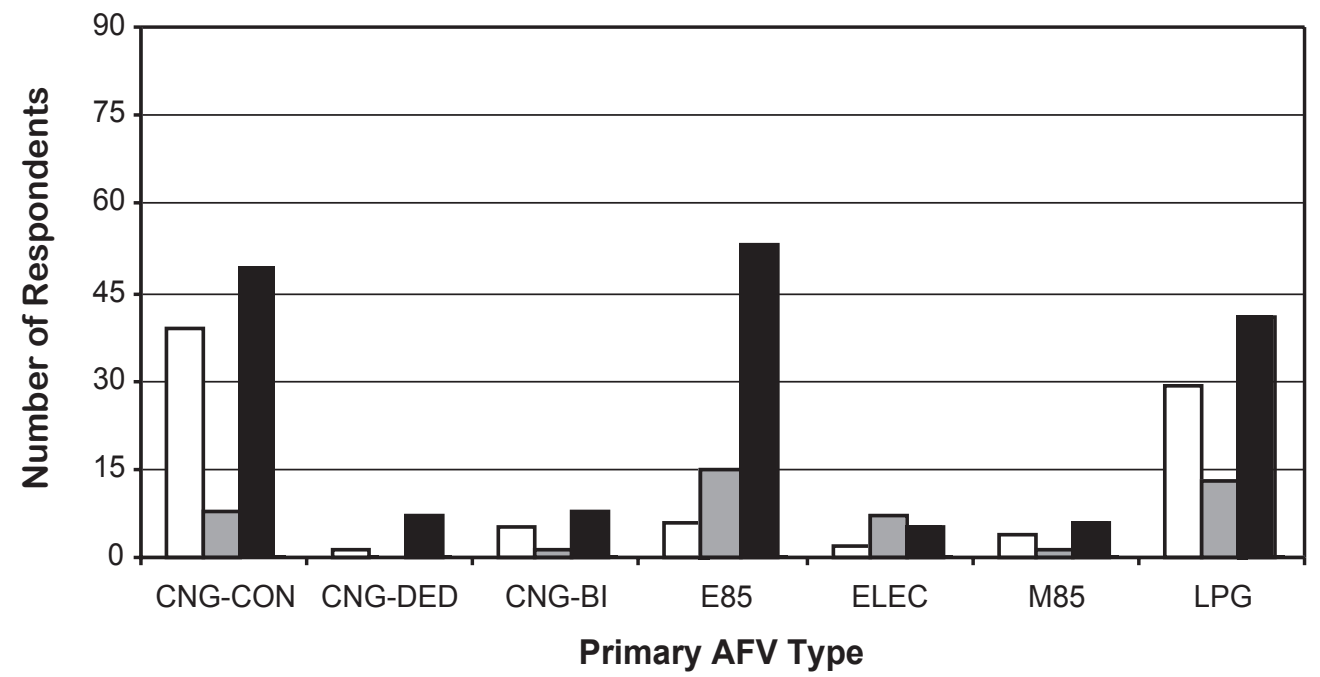

口Don't want $\quad \square$ Want $\quad$ No preference

Figure 7. City fleet manager responses to "how acceptable are AFVs to drivers?" by fleet's primary AFV type

Primary AFV Type
Fleet managers were asked whether their fleet vehide drivers specifically want AFVs. The responses by primary AFV type are summarized in Figure 6 for the state fleet managers and in Figure 7 for the city fleet managers. In both the state and city results, with the exception of fleets whose primary AFV type is electric vehicles, more fleet managers said their drivers do not indicate a preference for or against use of AFVs. In regards to ELEC vehicles, most fleet managers - state and city_indicated drivers want to drive the electric vehicles. It is worth noting that many fleet managers al so indicated that drivers generally do not have a choice of what vehicle they are assigned. Among the state fleet managers who indicated their drivers do not want to drive AFVs, the most common reason they gave was the limited avail ability of the alternative fuel. Similarly, city fleet managers reported vehicle performance problems, followed closely by limited vehicle range, as the most common reason drivers did not want to drive AFVs.

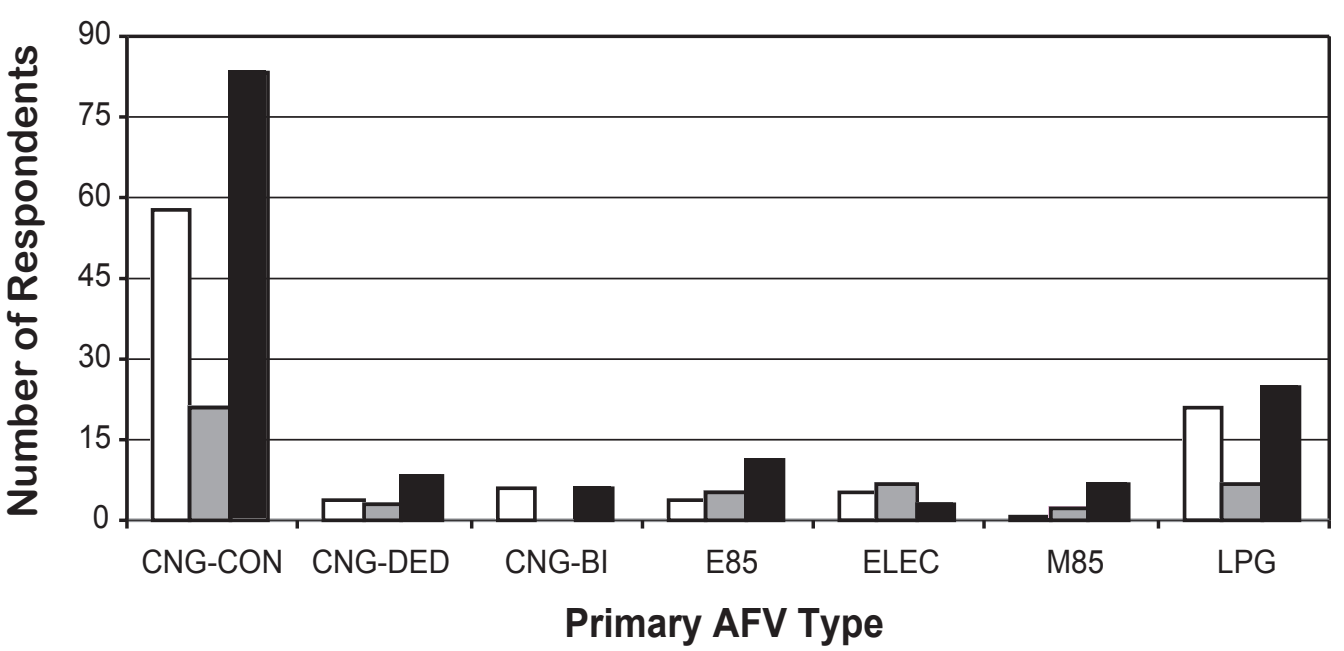

$\square$ Don't want $\quad \square$ Want $\quad$ No preference 


\section{Alternative Fuel Availability}

Fleet managers were questioned about the availability of al ternative fuel in the area where their fleet operates. More than $72 \%$ of the state fleet managers and nearly $80 \%$ of the city fleet managers indicated an al ternative fuel station is reasonably nearby. State and city fleet manager responses by primary AFV type are summarized in Figures 8 and 9, respectively. Alternative fuel stations were reported to be reasonably dose to $60 \%$ or more of respondents operating most of the AFV types. However, it appears that state fleet managers operating M85 vehicles and city fleet managers operating dedicated CNG vehicles as their primary AFV type have less access to the alternative fuel.

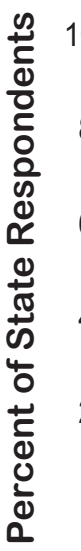

$$
\begin{aligned}
& 100 \\
& 80 \\
& 60 \\
& 40 \\
& 20 \\
& 0
\end{aligned}
$$

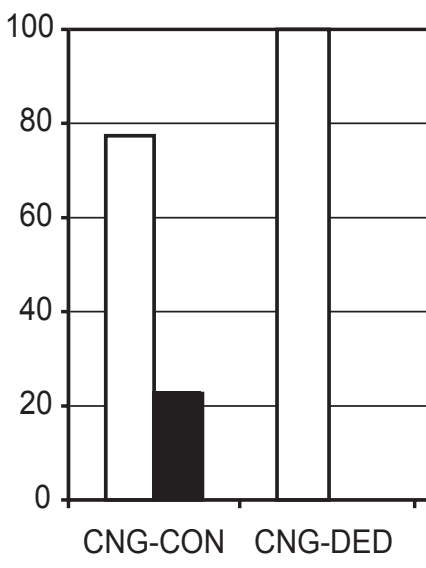

CNG-CON CNG-DED

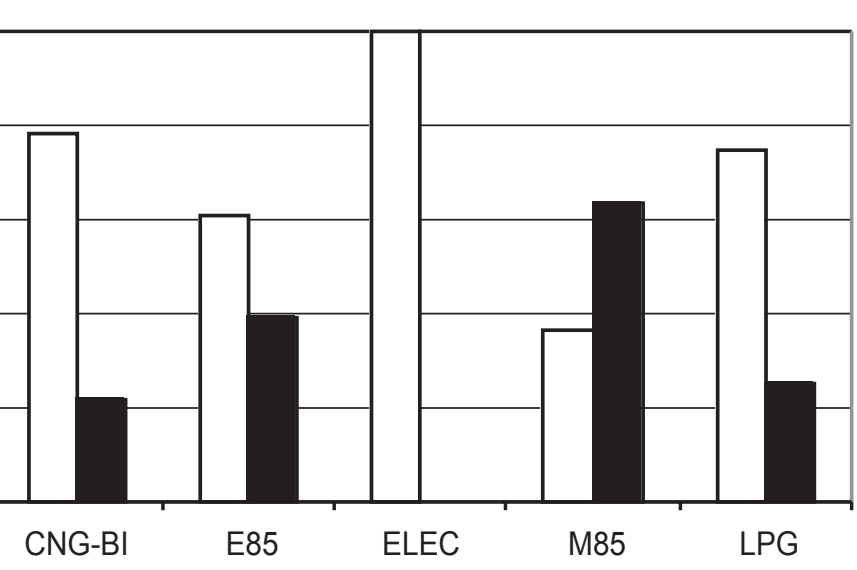

Primary AFV Type no

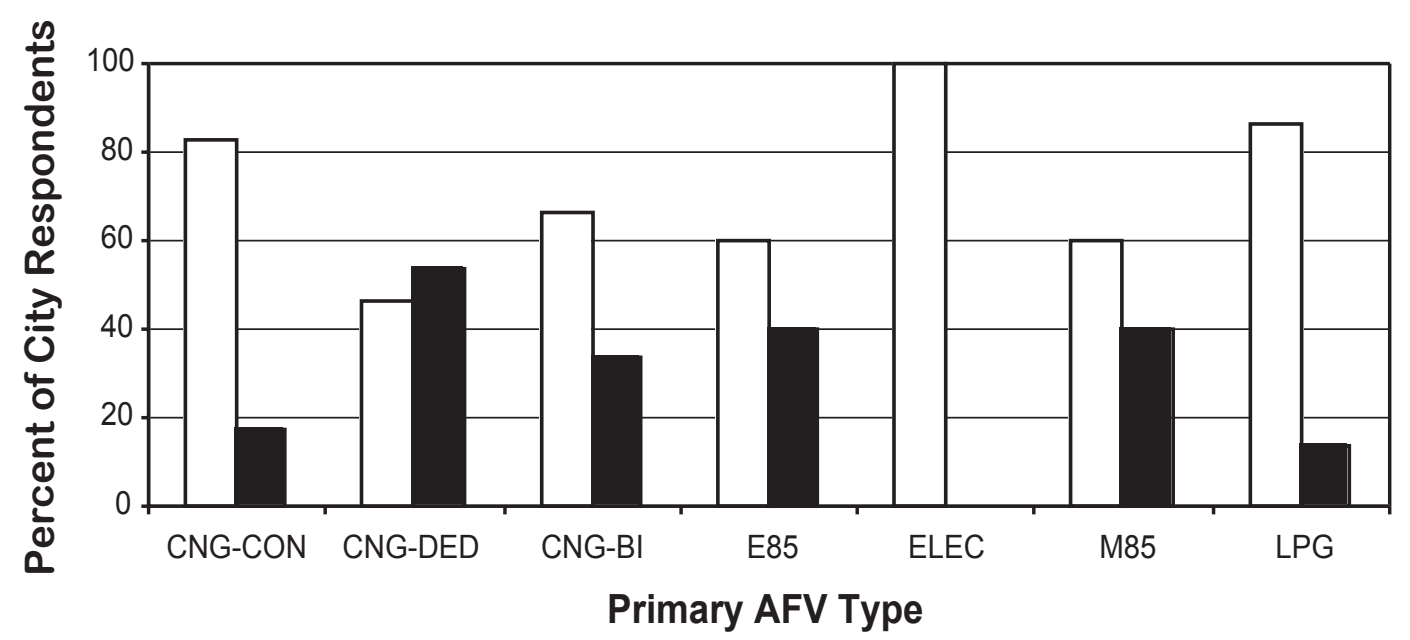

Figure 8. State fleet manager responses to "is there an alternative fuel station nearby?" by primary AFV type in fleet
Figure 9. City fleet manager responses to "is there an alternative fuel station nearby?" by primary AFV type in fleet 
In a related question, fleet managers were asked the type of fueling station used most often by their AFV fleets. Specifical ly they were asked whether they used an on-site, a public or a local private station. Most state and city fleet managers ( $55.7 \%$ and $51.2 \%$, respectively) reported that public stations are used by their AFV fleets, as shown in Figure 10. On-site refueling stations were the least common types of station used according to both the state and city fleet managers.

\section{Fueling Practices}

Fleet managers were asked whether their AFVs are usually fueled with alternative fuel or gasoline The responses are summarized in Figure 1la and $11 \mathrm{~b}$, and include only responses from fleet managers whose primary AFV types are bi-fuel and flexiblefuel vehicles (operators of dedicated vehicles must use the design fuel or not use their vehicle). Overall, $92.7 \%$ ( 278 of 300 ) of the state respondents and $89.5 \%$ ( 257 of 287 ) of the city respondents indicated their primary AFV types are either bi-fuel or flexiblefuel AFVs. Most of these state and city fleet managers (89.9\% and $86.8 \%$, respectively) responded that the AFVs in their fleets are mostly operated on al ternative fuel. When the state results were analyzed by region, there were differences in the percent of responses among the regions, but these differences were not statistically significant. In addition, no difference was found in fuel use based on the responses from city fleet managers when grouped by Clean Cities and other sel ected cities (see Figures A-1 and A-2 in the Appendix). These findings are different from those in the survey of federal fleet managers, where only about $63 \%$ of respondents indicated their bi-fuel or flexiblefuel AFVs are operated on alternative fuel most of the time

Figure 10. Fleet manager responses about the type of fueling station used by the AFV fleet

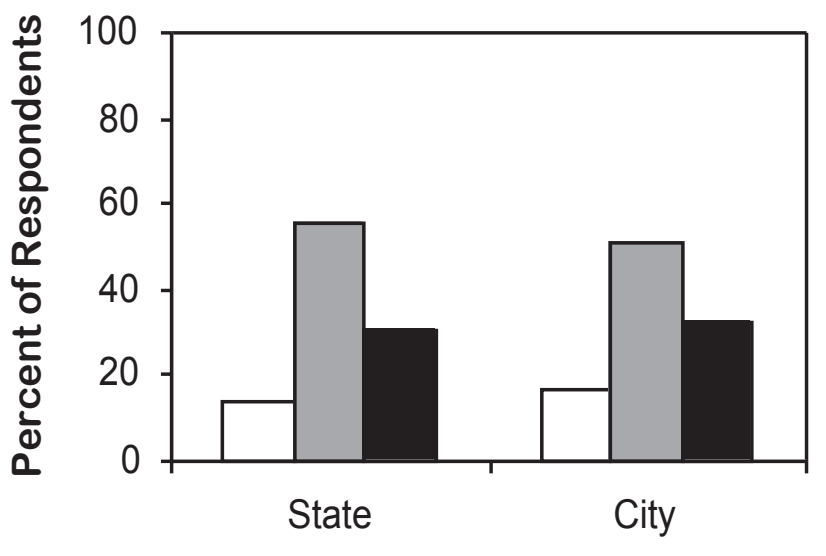

All AFV Types

口On-site station $\square$ Public station Private station 


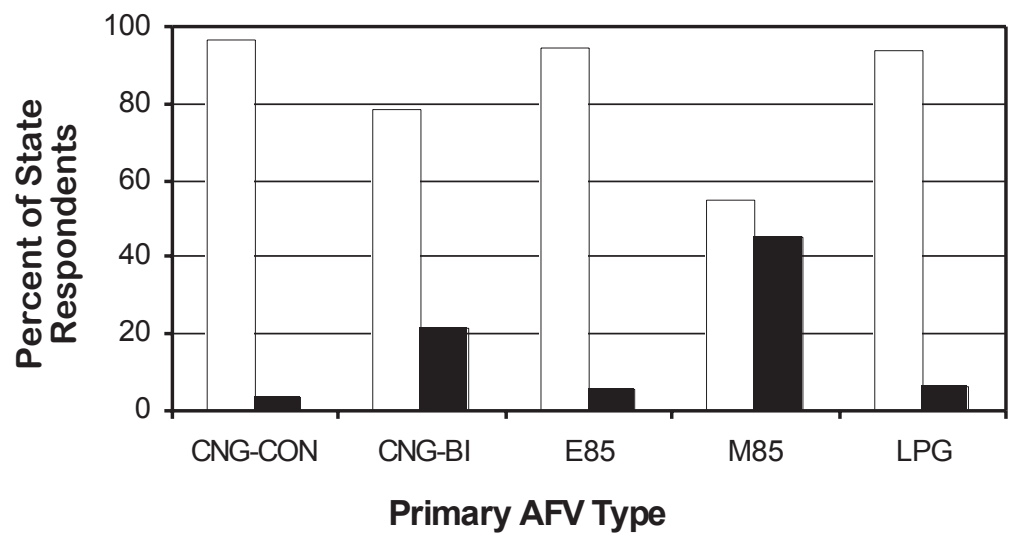

(a)

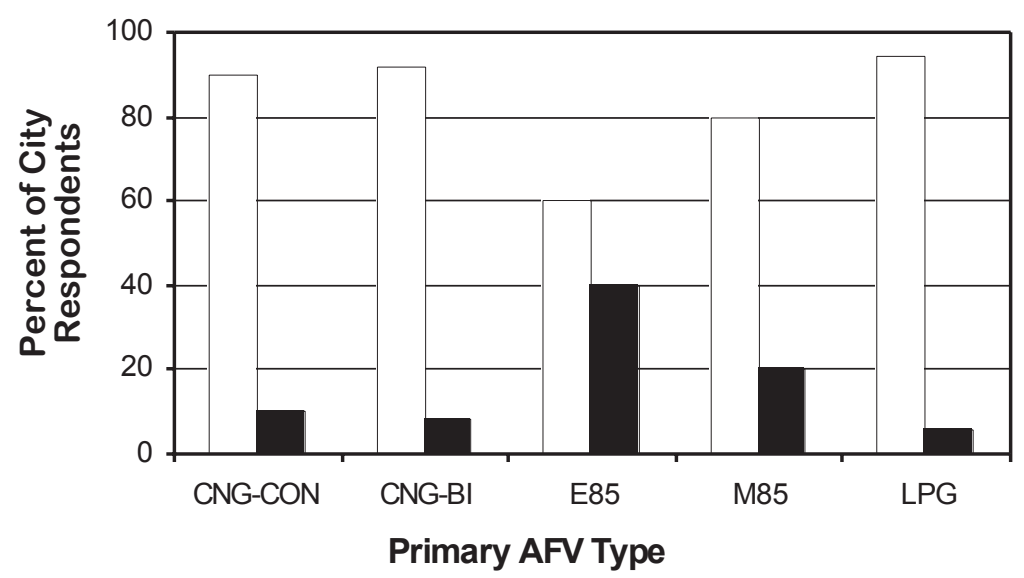

(b)
Figure 11. Fleet manager responses to "what fuel are your AFVs usually operated on?"- (a) state and (b) city, by primary AFV type in the fleet

\section{Vehicle Performance}

Fleet managers were asked if their drivers tended to report more vehicle performance complaints about AFVs or about similar gasoline vehicles. The results for the state and city fleet managers, which are summarized in Figure 12 , were very similar, with the majority of both $(59.7 \%$ of state respondents and $53.7 \%$ of city respondents) indicating they get the same amount of complaints about AFVs and gasoline vehicles. Slightly more than $34 \%$ of the state respondents and $39 \%$ of the city respondents indicated that they receive more complaints about AFVs than gasoline vehicles. Finally, only $6 \%$ of state and $7 \%$ of city fleet managers said they receive more complaints about their gasoline vehicles. 
Figure 12. Responses to "which vehicle type do you receive more complaints about?"
Figure 13. State fleet manager responses to "which vehicle type do you receive more complaints about?" by primary AFV type

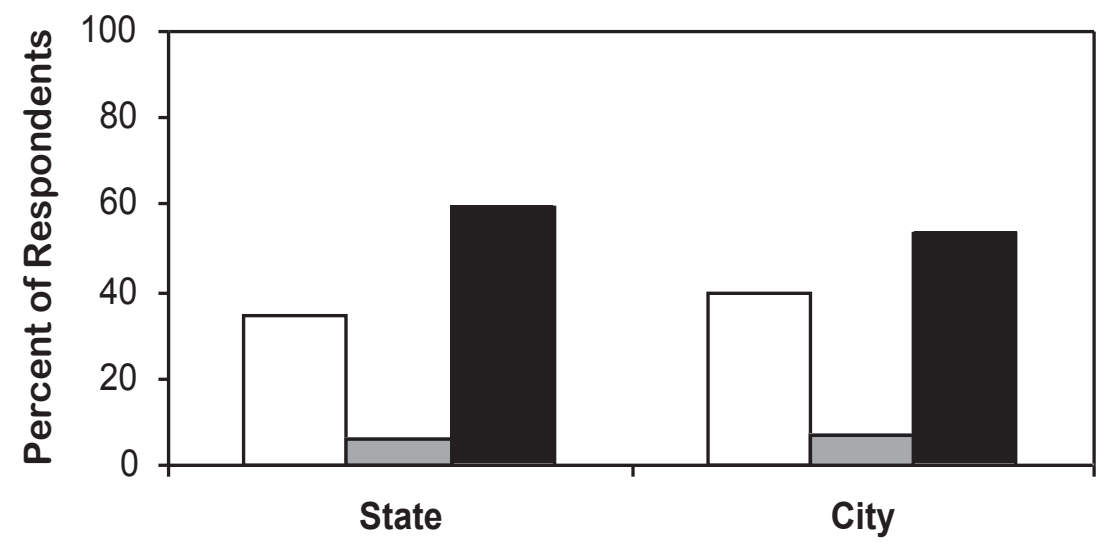

$\square$ AFVs $\quad \square$ Gasoline vehicles Equal number about each

When the responses were grouped by region, state fleet managers in the West were found to have reported significantly more complaints about AFVs than their counterparts in the other regions (52.6\% of responses compared to $30.4 \%$ in the Northeast, $25.0 \%$ in the Midwest, and $29.2 \%$ in the South, respectively). The difference was significant at $>99 \%$ confidence level $\left(\chi^{2}=18.67\right.$, d.f. $=6$ ). No difference was found in reports of complaints received when the city fleet manager data were grouped by Clean Cities and other selected cities.

When the fleet manager responses about driver complaints were evaluated by primary AFV type, no statistically significant difference was found for the city fleet manager responses. However, differences were seen among state fleet manager responses. The state fleet managers operating CNGCONs, CNG-OEMs and M85 vehides as their primary AFVs reported significantly more complaints about their AFVs than fleets operating the other AFV types (see Figure 13). The differences among state fleet manager responses were found to be statistical ly significant at a $>99 \%$ confidence level $\left(\chi^{2}=29.16\right.$, d.f. $\left.=12\right)$.

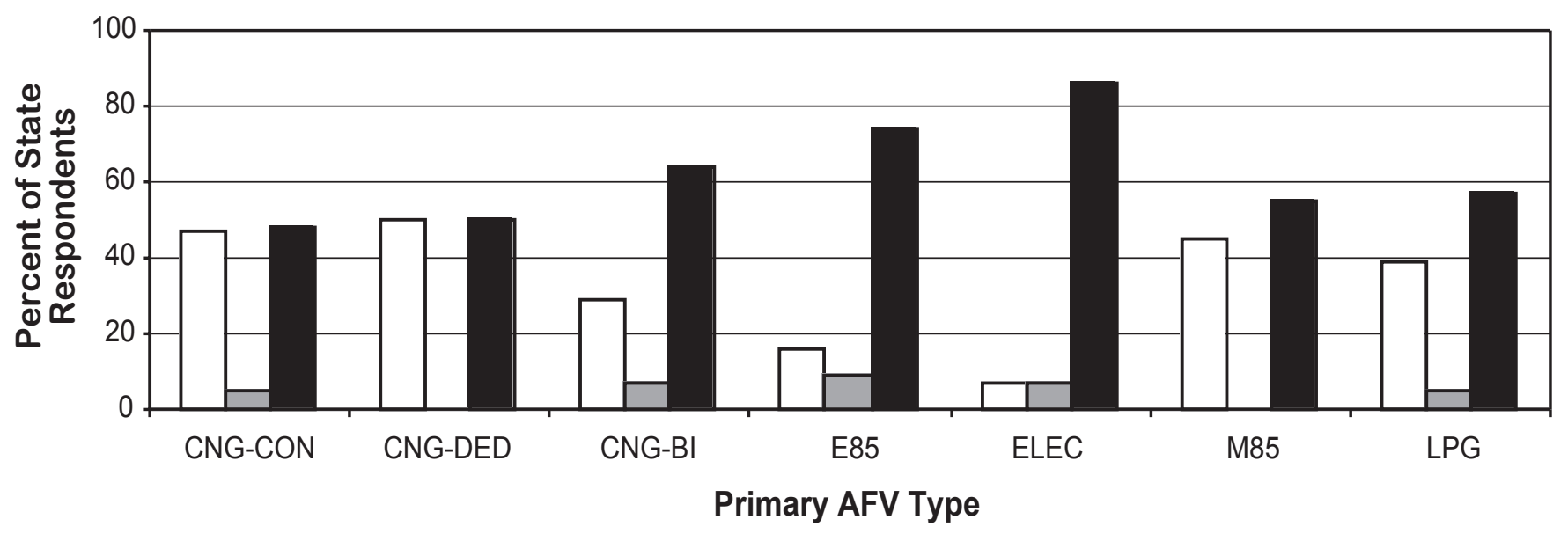

$\square$ more about AFVs $\square$ more about gasoline $\quad$ equal number 
Fleet managers were asked whether they had received any of eight specific performance-related complaints about their AFVs in the last month. The number of state and city fleet managers reporting specific complaints is tabulated in Table 3 and 4, respectively. The data in these tables are grouped by primary AFV for each of the eight specific performancerelated complaints, and the number of fleet managers reporting complaints. Twenty-eight percent of the state and 33\% of the city fleet managers reported receiving at least one of the performance complaints about their AFVs. The most commonly reported complaints for both groups of fleet managers were vehides "lacking power," followed by vehicles being "hard to start."

Table 3. State fleet manager reports of specific performance-related complaints about AFVs, by primary AFV type in the fleet

\begin{tabular}{|c|c|c|c|c|c|c|c|c|c|c|c|c|c|c|}
\hline \multirow[b]{3}{*}{ Problem Reported } & \multicolumn{13}{|c|}{ Primary AFV Type } & \multirow[b]{2}{*}{ TOTAL } \\
\hline & \multicolumn{2}{|c|}{$\overline{\text { CNG-CON }}$} & \multicolumn{2}{|c|}{ CNG-DED } & \multicolumn{2}{|c|}{ CNG-BI } & \multicolumn{2}{|c|}{ E85 } & \multicolumn{2}{|c|}{ ELEC } & \multicolumn{2}{|c|}{ M85 } & PROPANE & \\
\hline & No. & $\%$ & No. & $\%$ & No. & $\%$ & No. & $\%$ & No. & $\%$ & No. & $\%$ & No. $\%$ & No. $\%$ \\
\hline Hard to start & 12 & 18.8 & 1 & 33.3 & 1 & 16.7 & 4 & 25.0 & 0 & 0.0 & 2 & 25.0 & $15 \quad 19.5$ & 3520.1 \\
\hline Stall after starting & 4 & 6.3 & 0 & 0.0 & 0 & 0.0 & 0 & 0.0 & 0 & 0.0 & 1 & 12.5 & 6.5 & 5.7 \\
\hline Stall in traffic & 7 & 10.9 & 0 & 0.0 & 0 & 0.0 & 2 & 12.5 & 0 & 0.0 & 0 & 0.0 & 7.8 & 8.6 \\
\hline Poor idle & 6 & 9.4 & 0 & 0.0 & 2 & 33.3 & 1 & 6.2 & 0 & 0.0 & 0 & 0.0 & 15.6 & 12.1 \\
\hline Hesitation & 7 & 10.9 & 0 & 0.0 & 0 & 0.0 & 1 & 6.2 & 0 & 0.0 & 2 & 25.0 & 16.9 & 13.2 \\
\hline Lack of power & 22 & 34.4 & 2 & 66.7 & 3 & 50.0 & 5 & 31.3 & 0 & 0.0 & 2 & 25.0 & 26.0 & $54 \quad 31.0$ \\
\hline Engine ping & 2 & 3.1 & 0 & 0.0 & 0 & 0.0 & 0 & 0.0 & 0 & 0.0 & 0 & 0.0 & 1.3 & 1.7 \\
\hline Check engine light on & 4 & 6.3 & 0 & 0.0 & 0 & 0.0 & 3 & 18.8 & 0 & 0.0 & 1 & 12.5 & 6.5 & 7.5 \\
\hline Total & 64 & 100 & 3 & 100 & 6 & 100 & 16 & 100 & 0 & 0 & 8 & 100 & 100 & 174100 \\
\hline \multicolumn{15}{|c|}{ Fleet Managers Reporting Complaints } \\
\hline Number & \multicolumn{2}{|c|}{29 of 96} & \multicolumn{2}{|c|}{3 of 8} & \multicolumn{2}{|c|}{3 of 14} & \multicolumn{2}{|c|}{13 of 74} & \multicolumn{2}{|c|}{0 of 14} & \multicolumn{2}{|c|}{3 of 11} & 33 of 83 & 84 of 300 \\
\hline$\%$ & \multicolumn{2}{|c|}{30.2} & \multicolumn{2}{|c|}{37.5} & \multicolumn{2}{|c|}{21.4} & \multicolumn{2}{|c|}{17.6} & \multicolumn{2}{|c|}{0.0} & \multicolumn{2}{|c|}{27.3} & 39.7 & 28.0 \\
\hline
\end{tabular}

Table 4. City fleet manager reports of specific performance-related complaints about AFVs, by primary AFV type in the fleet

\begin{tabular}{|c|c|c|c|c|c|c|c|c|c|c|c|c|c|c|c|}
\hline \multirow[b]{3}{*}{ Problems Reported } & \multicolumn{14}{|c|}{ Primary AFV Type } & \multirow[b]{2}{*}{ TOTAL } \\
\hline & \multicolumn{4}{|c|}{ CNG-CON CNG-DED } & \multicolumn{2}{|c|}{ CNG-BI } & \multicolumn{2}{|c|}{ E85 } & \multicolumn{2}{|c|}{ ELEC } & \multicolumn{2}{|c|}{ M85 } & \multicolumn{2}{|c|}{ LPG } & \\
\hline & No. & $\%$ & No. & $\%$ & No. & $\%$ & No. & $\%$ & No. & $\%$ & No. & $\%$ & No. & $\%$ & No. $\%$ \\
\hline Hard to start & 21 & 18.7 & 0 & 0 & 1 & 7.1 & 3 & 50 & 0 & 0 & 0 & 0 & 11 & 24.4 & $36 \quad 19.0$ \\
\hline Stall after starting & 7 & 6.3 & 0 & 7 & 2 & 14.3 & 0 & 0 & 0 & 0 & 1 & 25 & 4 & 8.9 & 7.4 \\
\hline Stall in traffic & 14 & 12.5 & 1 & 25 & 2 & 14.3 & 1 & 16.7 & 0 & 0 & 1 & 25 & 3 & 6.7 & $22 \quad 11.7$ \\
\hline Poor idle & 7 & 6.3 & 0 & 0 & 2 & 14.3 & 0 & 0 & 0 & 0 & 2 & 50 & 7 & 15.6 & 9.5 \\
\hline Hesitation & 10 & 8.9 & 1 & 25 & 1 & 7.1 & 0 & 0 & 2 & 50 & 0 & 0 & 8 & 17.8 & 11.7 \\
\hline Lack of power & 42 & 37.5 & 1 & 25 & 4 & 28.7 & 2 & 33.3 & 2 & 50 & 0 & 0 & 11 & 24.4 & 32.8 \\
\hline Engine ping & 3 & 2.7 & 1 & 25 & 1 & 7.1 & 0 & 0 & 0 & 0 & 0 & 0 & 0 & 0 & 2.6 \\
\hline Check engine light on & 8 & 7.1 & 0 & 0 & 1 & 7.1 & 0 & 0 & 0 & 0 & 0 & 0 & 1 & 2.2 & 5.3 \\
\hline Total & 112 & 100 & 4 & 100 & 14 & 100 & 6 & 100 & 4 & 100 & 4 & 100 & 45 & 100 & 189100 \\
\hline \multicolumn{16}{|c|}{ Fleet Managers Reporting Complaints (by primary AFV type) } \\
\hline Number & \multicolumn{2}{|c|}{57 of 162} & \multicolumn{2}{|c|}{$\begin{array}{c}3 \text { of } 15 \\
200\end{array}$} & \multirow{2}{*}{\multicolumn{2}{|c|}{$\begin{array}{c}4 \text { of } 12 \\
33.3\end{array}$}} & \multicolumn{2}{|c|}{5 of 20} & \multicolumn{2}{|c|}{2 of 15} & \multicolumn{2}{|c|}{3 of 10} & \multicolumn{2}{|c|}{21 of 53} & 95 of 287 \\
\hline$\%$ & \multicolumn{2}{|c|}{35.2} & \multicolumn{2}{|c|}{20.0} & & & \multicolumn{2}{|c|}{25.0} & \multicolumn{2}{|c|}{13.3} & \multicolumn{2}{|c|}{30.0} & \multicolumn{2}{|c|}{39.6} & 33.1 \\
\hline
\end{tabular}


Overall, a considerable number of performancerelated complaints about AFVs were reported by these state and city fleet managers. The number of these fleet managers reporting vehicle performance problems was markedly higher than the results seen in a previous survey (Whalen and Coburn, 1997) involving federal government fleet managers ( $28 \%$ of state and $33 \%$ of city fleet managers reported performance complaints compared to just over $5 \%$ of the federal fleet managers). One possible reason is the disparity in the composition of the fleets. Most respondents in the federal fleet survey reported their primary AFVs to be OEM models, whereas most of the city and state fleet respondents indicated their primary AFVs to be CNG or LPG conversions. In spite of the differences in the fleets and the number of fleet managers reporting complaints in the two surveys, one common finding is that more fleet managers whose primary AFV types were conversions reported receiving complaints than fleet managers whose primary AFVs were OEMs. It is also important to note that in the previous survey an attempt was made to bal ance the number of surveys among the AFV types, whereas no attempt was made to achieve such a balance in the current survey.

\section{Vehicle Maintenance}

Most responding state (79\%) and city (84\%) fleet managers indicated that maintenance on the vehicles in their fleet is performed in their own shops. Therefore, these fleet managers are generally informed and knowledgeable about maintenance and repair of their fleet vehicles. Most $(90.6 \%$ of state and $89.2 \%$ of city fleet managers) indicated that no different or additional scheduled maintenance was required on their primary AFVs. These results are similar to those from the federal fleet manager survey, where $92 \%$ of the fleet managers indicated no difference in scheduled maintenance for AFVs. Figure 14 shows the results by primary AFV type for both the city and state fleet managers. The differences among the primary AFV types were not significant for the city fleet managers. However, the differences among state fleet manager responses were significant at a $>99 \%$ confidence level $\left(\chi^{2}=18.35\right.$, d.f. $\left.=6\right)$, with a higher percentage of fleets having M85 and electric vehicles as their primary AFVs reporting additional scheduled maintenance. When asked to identify what types of additional scheduled maintenance were required, no one mai ntenance item was dominant, although several respondents indicated oil changes or special oil.

Survey participants were also asked about the frequency and types of unscheduled maintenance, and Figure 15 summarizes these results. As in the case of the scheduled maintenance results, most interviewees (94.3\% of state and $90.5 \%$ of city fleet managers) responded that they experienced no difference in the types or frequency of unscheduled maintenance for their primary AFVs. Again, these results are similar to those from the federal fleet manager survey, where $94 \%$ of respondents indicated no difference in 


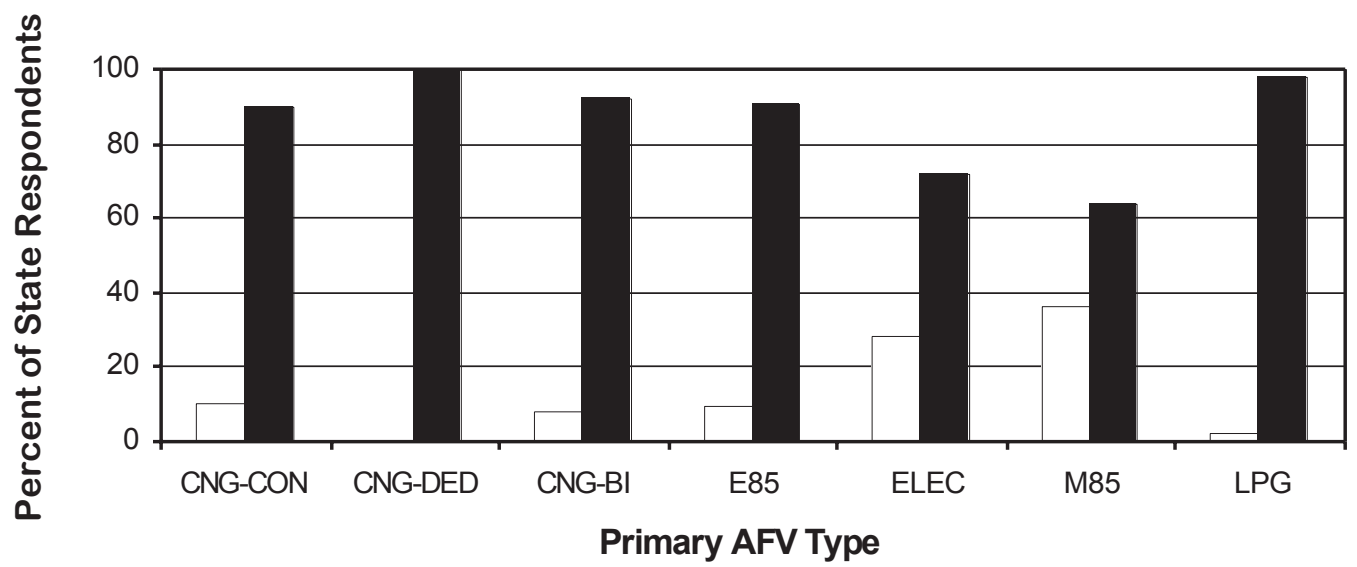

(a)

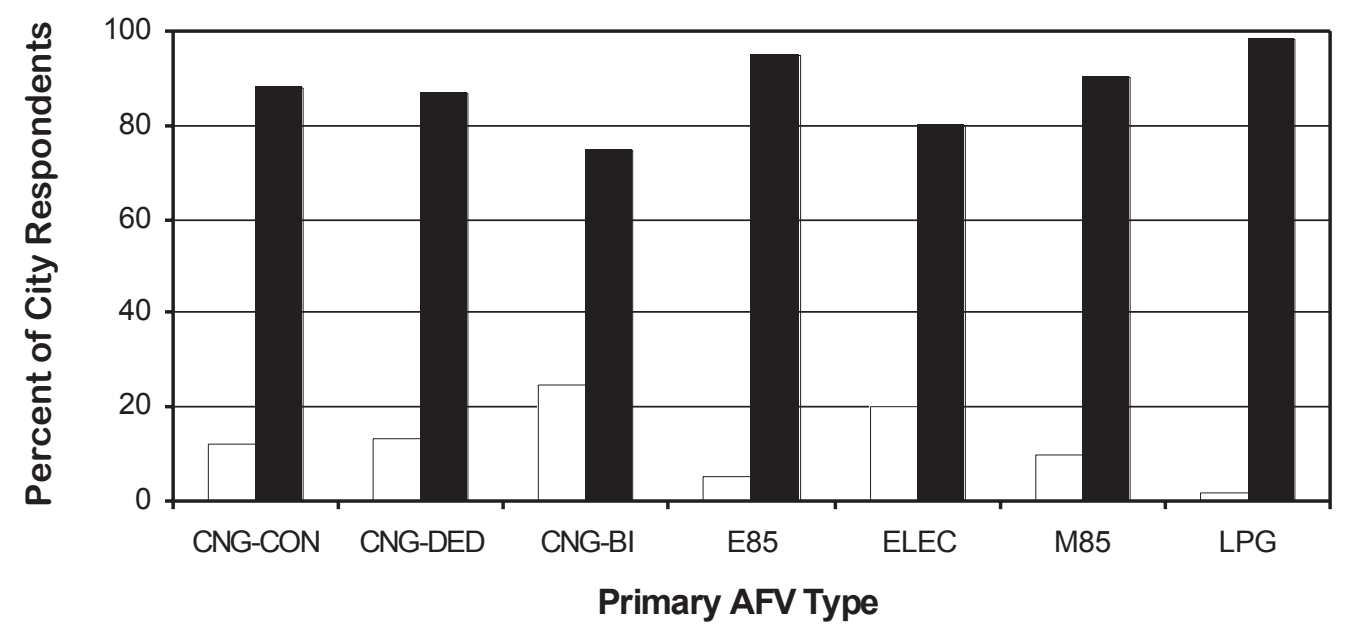

(b)

$\square$ Yes $\quad$ No

Figure 14. Responses to "do your AFVs require more or different scheduled maintenance than similar gasoline vehicles?" by primary AFV type in fleet- (a) state and (b) city fleet managers

unscheduled maintenance of AFVs. The differences by primary AFV type were not significant for either the state or city manager responses. When the fleet managers who reported differences in unscheduled maintenance were asked what types of unscheduled repairs were common, several of both the state and city fleet managers reported fuel system related repairs. The most reports of this type were from fleet managers whose primary AFV type is CNG-CON or LPG vehides. 


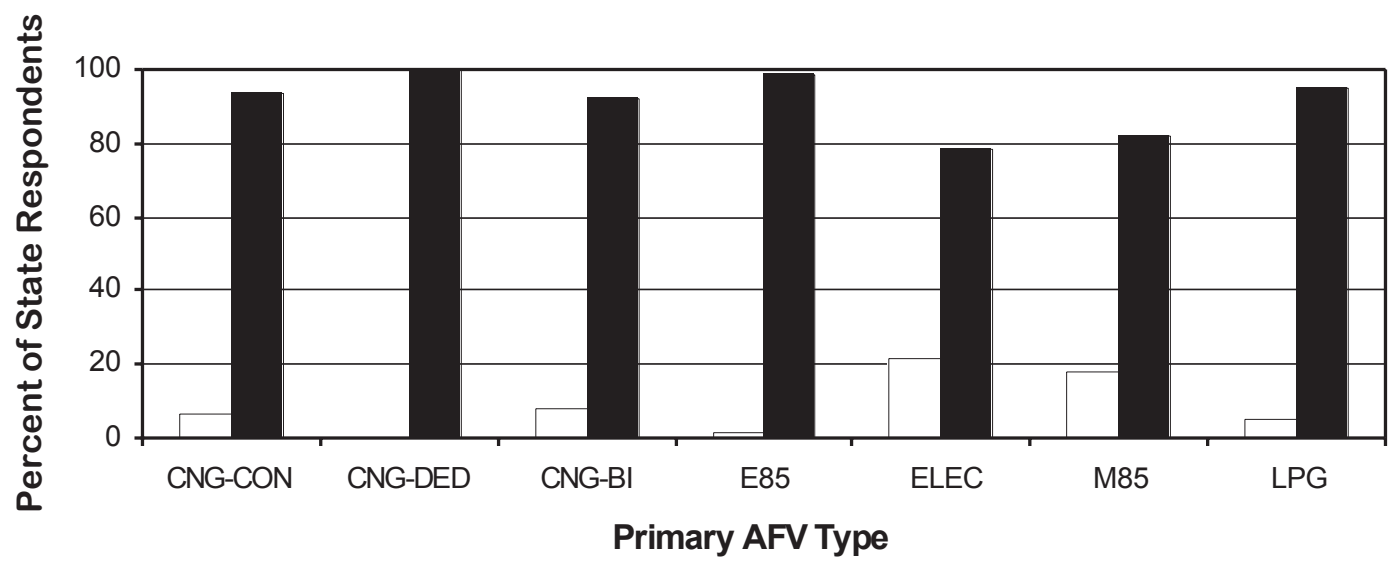

(a)

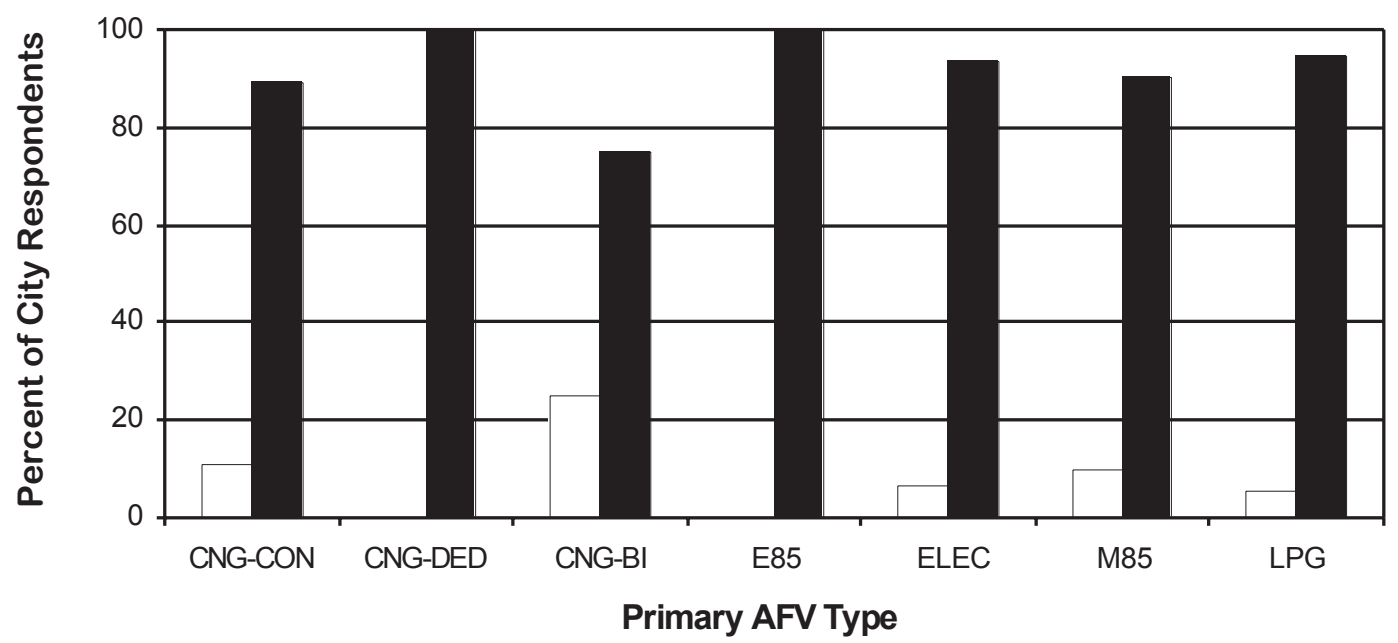

(b)

$\square$ Yes $\quad$ No

Figure 15. Responses to "do your AFVs require more or different unscheduled maintenance than similar gasoline vehicles?" by primary AFV type- (a) state and (b) city fleet managers

Grouping the state fleet manager responses about scheduled maintenance by region did not reveal any regional differences (see Figure A-11). However, when the unscheduled maintenance responses were grouped by region, some regional differences were uncovered (see Figure A-13). Compared to the total number of fleet managers responding, proportional ly more state fleet managers in the Midwest reported no difference in unscheduled maintenance ( $98.7 \%$ responded this way), while proportionally fewer fleet managers in the South (89.6\%) reported no such difference On the other hand, when the city fleet manager responses concerning scheduled and unscheduled maintenance were grouped by Clean Cities participants and other cities, the percentage distributions of responses were no different than the overall percentage distributions (see Figures A-12 and A-14). 
Another maintenancerelated question dealt with AFV vehicle downtime compared to that of similar gasoline vehicles. Approximately $85 \%$ of the state fleet managers and $82 \%$ of the city fleet managers indicated no difference in downtime between the AFVs and the gasoline vehicles in their fleets. Most of these fleet managers ( $89 \%$ of state and $90 \%$ of city respondents) also reported that typical vehicle downtime in their fleets is less than one day per month. Of the remaining fleet managers who said there was a difference in vehicle downtime, just over $64 \%$ of the state respondents and nearly $55 \%$ of the city respondents indicated that the AFVs in their fleet typically have more downtime than gasoline vehicles.

\section{Vehicle 0 perational Costs}

Each of the state and city fleet managers was asked whether the costs associated with owning and operating AFVs differs from those of gasoline vehides. The results, grouped by AFV costs being higher, lower or about the same as those typically seen for gasoline vehicles, are summarized in Figure 16 . Some $40.6 \%$ of state fleet managers and $36.7 \%$ of city fleet managers indicated costs associated with AFVs are higher than those of similar gasoline vehides. However, most state fleet managers $(59.4 \%)$ and city fleet managers (63.3\%) responded that costs associated with AFVs are about the same or lower than those of gasoline vehides. The distribution of responses by fuel type varied somewhat, but the differences were not statistically significant. When the state responses were grouped by region and the city responses grouped by Clean Cities and other cities, no differences in the percentage distributions, compared to the overall distributions, were uncovered.

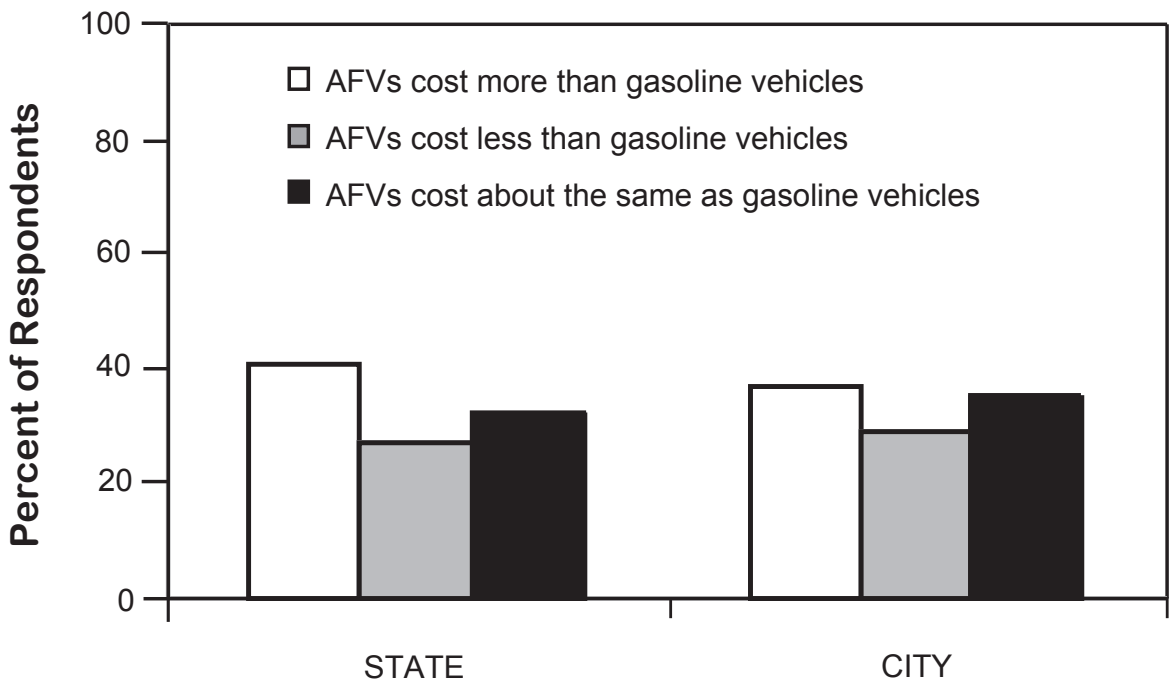

All AFV Types
Figure 16. Responses to "how do the costs of owning and operating AFVs compare to those of similar gasoline vehicles?" 


\section{0 verall Satisfaction}

Fleet managers were questioned about their overall satisfaction level with the AFVs in their fleets. They were specifically asked to think about performance, convenience, and any other factors that they thought were significant to operating AFVs in their fleets. The responses are summarized in Figure 17 by state and city, and by primary AFV type.

About $63 \%$ of both state and city fleet managers reported being very satisfied or leaning toward satisfied with their AFVs (see Figure 17a). Less than $20 \%$

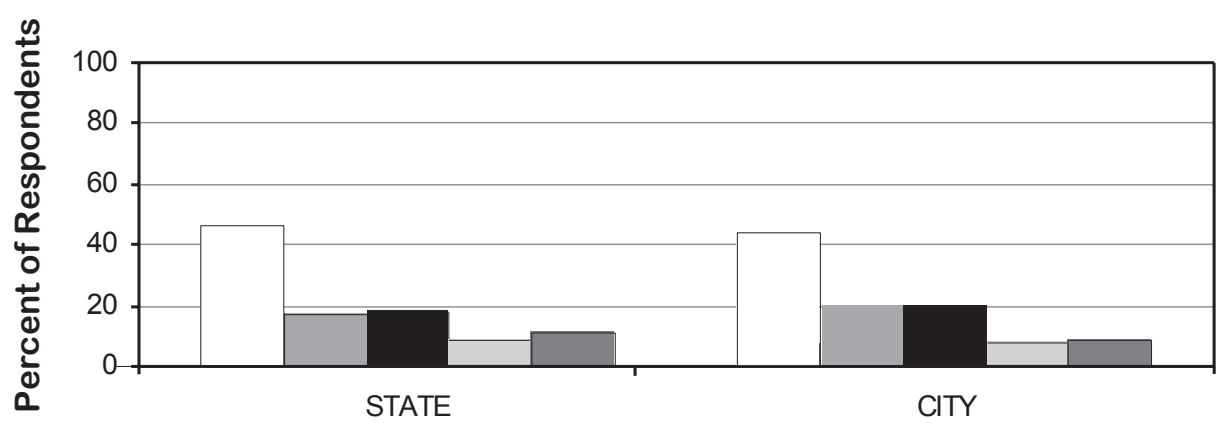

All AFV Types

(a)

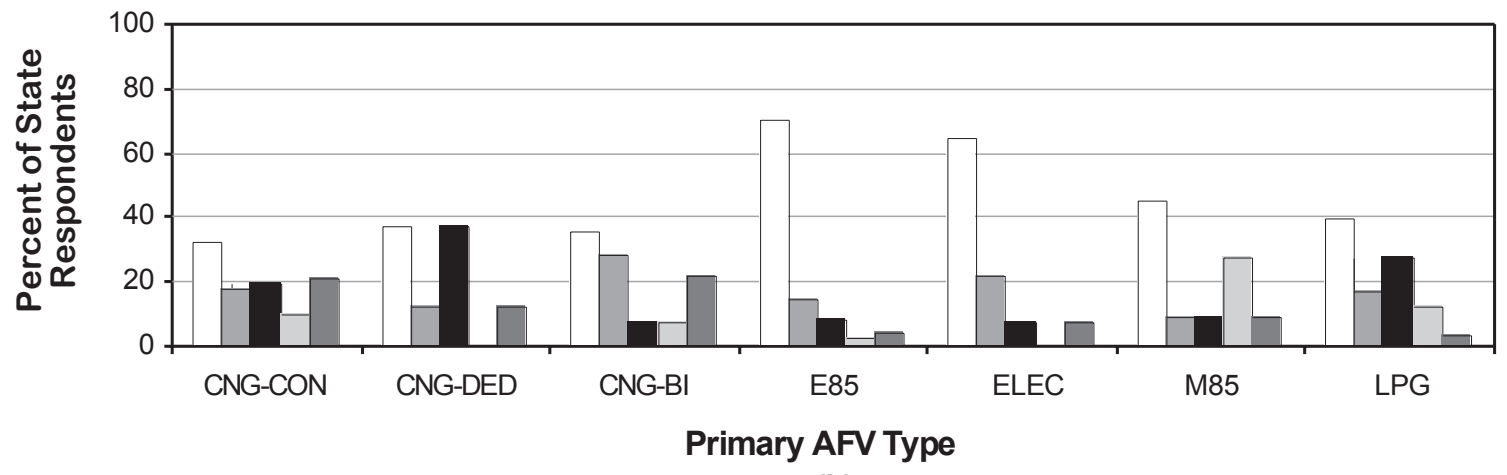

(b)

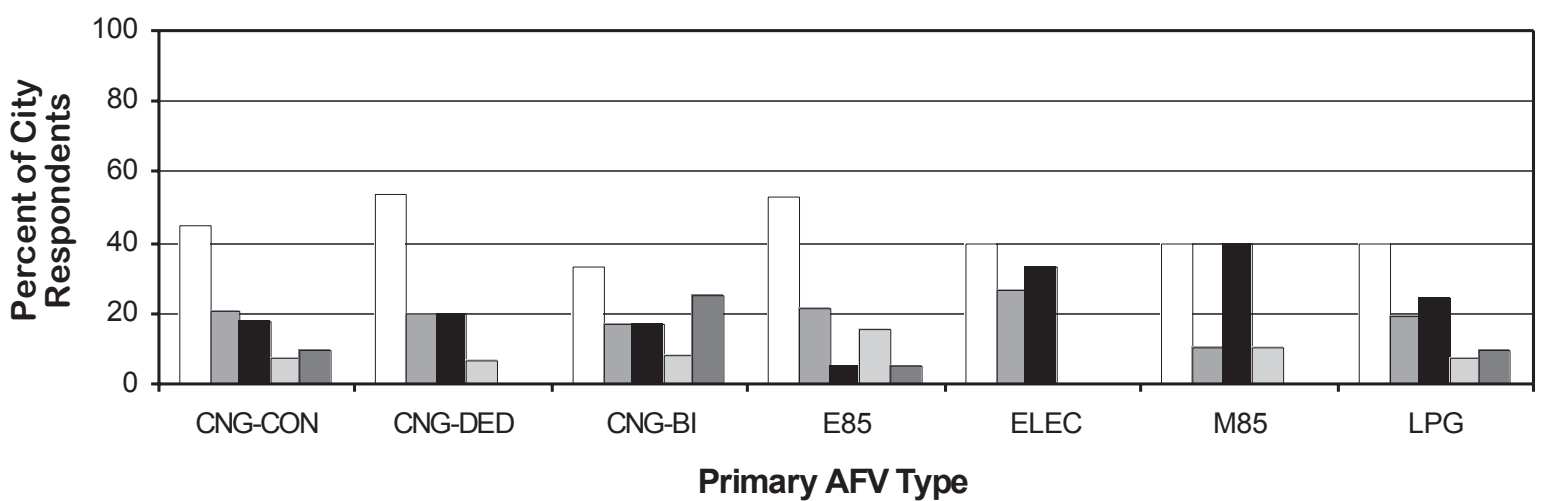

(c) 
of both the state and city fleet managers indicated they are dissatisfied or leaning toward dissatisfied with their AFVs. As might be expected, there were some differences in the distribution of responses by primary AFV type.

Figure $17 \mathrm{~b}$ and $17 \mathrm{c}$ present a summary of the state and city fleet manager response, respectively, by primary AFV type. Analysis indicated statistically significant differences only in the distribution of state fleet manager responses by primary AFV type $\left(\chi^{2}=29.16\right.$, d.f. $\left.=12, \alpha<0001\right)$. The greatest variations were in the frequencies of the most extreme ratings of very satisfied and dissatiffied. Among the state fleet managers, those operating E85 and electric vehides appear to be the most satisfied with their AFVs. More than $60 \%$ of the fleet managers with these AFVs types reported being very satisfied with their AFVs.

Figure 18 presents fleet manager responses grouped by region. Analysis indicated the distribution of responses by region are statistically significant $\left(\chi^{2}=24.3\right.$, d.f. $\left.=12, \alpha<02\right)$. In the Midwest, significantly more fleet managers reported leaning toward being satiffied or very satisfied overall with their fleet AFVs than in other regions (76.2\% compared to $63.1 \%$ in the Northeast, $66.3 \%$ in the South, and $45.5 \%$ in the West, respectively). Fleets operating E85 vehicles as their primary AFV type dominate the participating Midwest respondents. On the other hand, fleets managers from the West reported being dissatisfied with their AFVs at a rate nearly $10 \%$ higher than fleet managers in the other regions. Approximately $20 \%$ of fleet managers in the West reported being dissatisfied compared to $8.7 \%$ in the Northeast, $3.8 \%$ in the Midwest, and $10.5 \%$ in the South, respectively. Similar analysis of city fleet manager responses grouped by Clean Cities and other cities did not reveal any differences that were statistically significant.

Following the inquiry about overall satisfaction with AFVs, fleet managers were asked what one issue influenced them most in their ratings. Fleet managers who were dissatisfied or leaning toward dissatisfied most commonly reported poor vehicle performance and limited fuel availability as influencing their responses. The most common response from fleet managers who were very satisfied or leaning toward satisfied was the good performance of their AFVs.

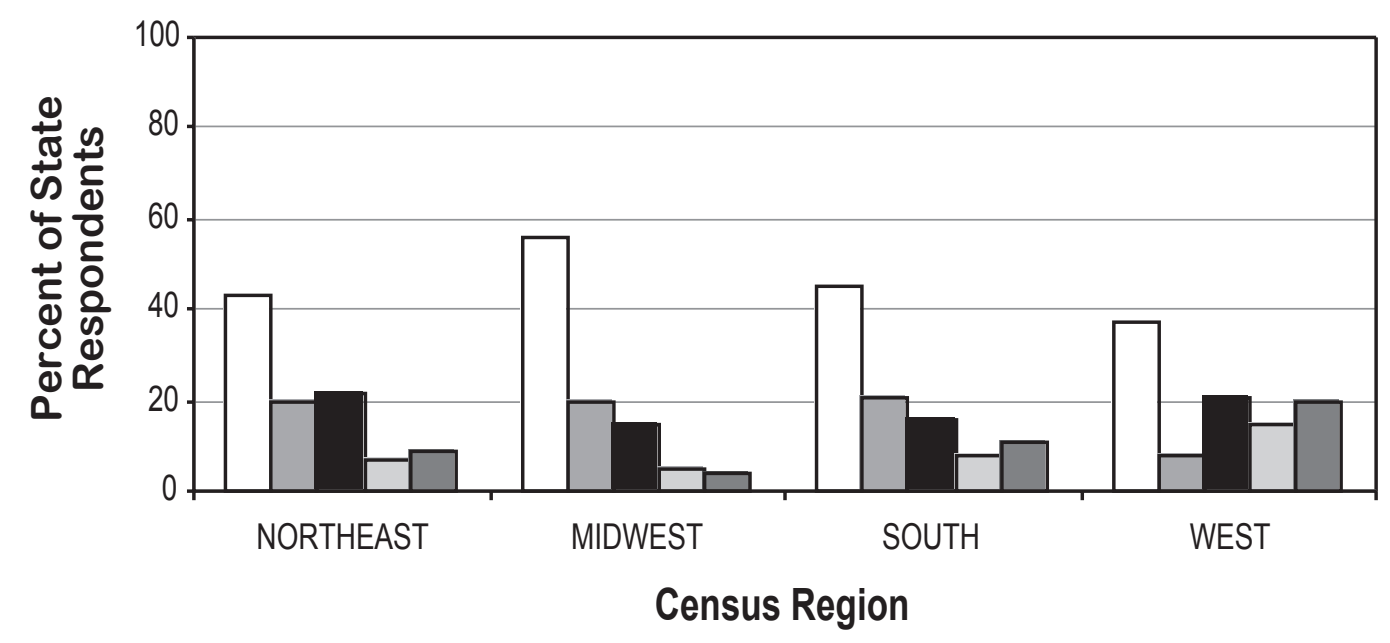

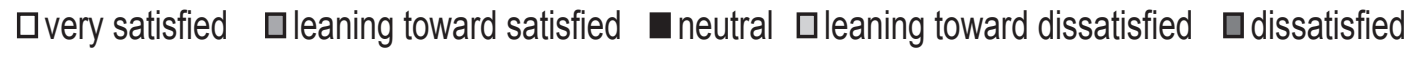




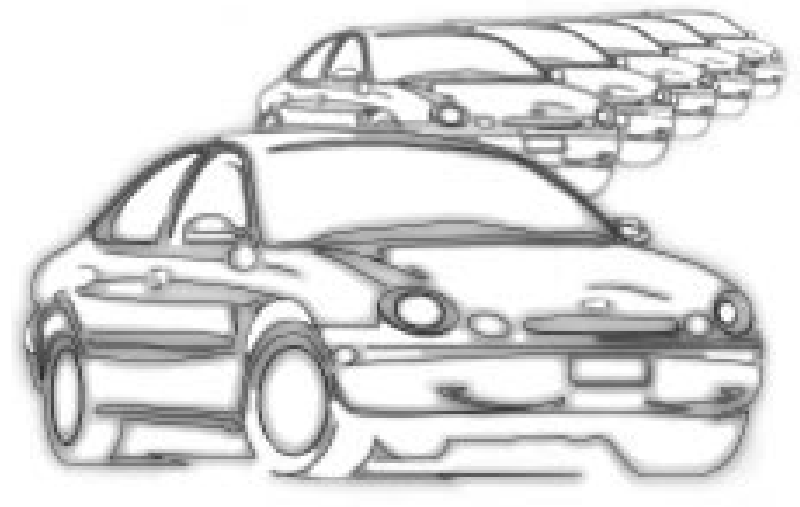

\section{Summary}

As a result of improving vehicle technology, production of more vehides by the OEMs, and changing government regulations, light-duty AFVs continue to be added to fleets - particularly federal, state, and local government fleets. Information on real-world experiences from fleets currently operating AFVs (such as that presented here) may be of value to other fleets that plan to add them, either voluntarily or in response to regulatory mandates.

This survey focused on obtaining state and local government fleet manager perspectives on the use, acceptability, and performance of AFVs. Randomly selected state and city fleet managers across the country provided candid feedback on the AFVs in their fleets. For the most part, these fleet managers provided favorable responses about AFV use and operation.

The state fleet managers and city fleet managers interviewed generally operate only a few AFVs, with most reporting 10 or fewer AFVs in their fleets. AFVs represent a relatively small proportion of the vehicles in these fleets. The 300 state fleet managers included in this survey reported having a total of 17,508 AFVs in their fleets: $6.4 \%$ of all their vehicles. The 287 city fleet managers included in this survey reported having a total of 8,128 AFVs in their fleets: $4.9 \%$ of all their vehicles. Aftermarket conversion (CNG and LPG) and flexible-fuel vehides were the most commonly reported primary AFV types among these fleets. Currently available fueling infrastructure may be driving fleets to purchase bi- and flexiblefuel vehicles, when other dedicated fuel vehicles might have more impact on reducing energy dependence and improving air quality.

Most of the interviewees said their drivers did not indicate a preference for or against using AFVs. The exception was fleets with electric vehicles. Fleet managers whose primary AFV type is electric had higher rates of drivers wanting to drive these vehicles. Because there are few in service, we suspect that there may be more curiosity about and interest in driving an electric vehicle than there is for the other types of AFVs.

Most state fleet and city fleet managers reported that alternative fuel stations were in close proximity to their fleet locations. Access to alternative fuel was reported to be most limited by state fleets operating M 85 and by city fleets operating dedicated CNG AFVs. Most fleets ( $55.7 \%$ of state and $51.2 \%$ of city fleets) indicated that they use public stations for fueling. Despite the fact that limited fuel avai lability was the most commonly cited reason that drivers do not want to drive AFVs, it appears from the fleet managers' responses that al ternative fuel is reasonably available to most of these fleets. 
Among fleet managers whose primary AFV types are bi-fuel or flexiblefuel vehicles, most respondents said that their AFVs are operated mostly on the alternative fuel. The alternative fuel use rate was higher than expected, and much higher than that reported in the previous federal fleet manager survey. Here, approximately $90 \%$ of state fleet managers and approximately $87 \%$ of city fleet managers reported that their AFVs use al ternative fuel $50 \%$ or more of the time; approximately $63 \%$ of the federal fleet managers responded this way.

The distribution of responses to questions related to performance complaints and maintenance indicate that performance of AFVs compares reasonably well with that of similar gasoline vehicles for many of these fleets. However, it is worthwhileto notethat some $34 \%$ of stateand 39\% of city fleet managers reported receiving more complaints about their AFVs than about their gasoline vehides.

When asked about specific complaints, $28 \%$ percent of state and $33 \%$ of city fleet managers reported receiving at least one of the eight specific performancerelated complaints, with "lacking power," and being "hard to start" being the most common. The rate of reports of specific performance complaints was much higher than in the previous federal fleet manager survey (Whalen and Coburn, 1997), where just over $5 \%$ of fleet managers reported complaints. It is al so worthwhile to note that in this survey $67 \%$ of state and $75 \%$ of city fleet managers identified their primary AFV type as an aftermarket conversion (CNG-CON or LPG); more than $80 \%$ of the complaints were from these fleet managers. This indicates that these fleets may be experiencing more problems with aftermarket conversion AFVs.

Despite more reports of complaints among these fleet managers, most ( $90 \%$ or more) reported no difference in the types or frequency of maintenance — scheduled or unscheduled-between AFVs and similar gasoline vehicles in the fleet. Most also reported no difference in downtime between AFVs and similar gasoline vehicles in their fleets. Responses about the costs associated with operating AFVs were dosely divided between reports that AFVs cost more, AFV cost less, and AFVs cost about the same as gasoline vehides, with slightly more reports that AFVs cost more than gasoline vehides to operate

About $63 \%$ of both state and city fleet managers combined reported being very satisfied overall or leaning toward being satisfied with the AFVs in their fleets. Fleets with electric and E85 vehicles as their primary AFV types tended to have higher percentages of satisfaction. Among state fleet managers, more fleet managers in the Midwest (which is dominated by E85fueled vehicles as the primary AFV type) reported being satisfied overall with their AFVs than those in any other region.

Clearly, al ternative fuel vehides are being used in fai r numbers by state and city government fleets across the country. These fleets have experience with all the types of AFVs currently available in the marketplace. Although there continue to be some fuel and performance issues associated with use of the different AFV types, these fleet managers' responses about AFV use, acceptability, and performance generally provide favorable feedback about their experiences with AFVs. 


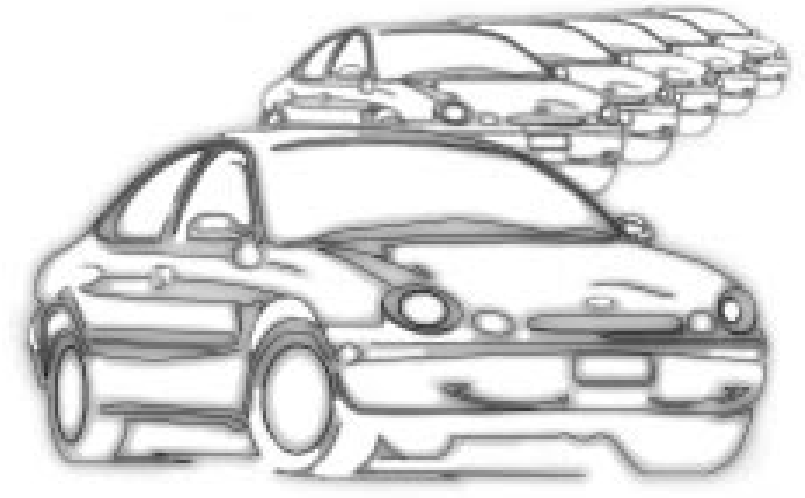

\section{Acknowledgments}

This work was sponsored by the Office of Technology Utilization, which is part of the Office of Transportation Technologies at the U.S. Department of Energy in Washington, D.C. Bill Gilbert served as the project manager for Petroleum Information/Dwights and Gary Starkey of PI/Dwights directed completion of all the telephone interviews.

Appreciation is extended to the numerous state and city fleet managers for their willingness to participate in this survey.

\section{References}

Energy Information Administration (EIA), December 1997, Alternatives to Traditional Transportation Fuels 1996, DOE/EIA-0585(96), Washington, DC: EIA Office of Coal, Nudear, Electric, and Alternate Fuels.

EIA, December 1996, Alternatives to Traditional Transportation Fuels 1995, DOE/EIA-0585(95), Washington, DC: ElA Office of Coal, Nudear, Electric, and Alternate Fuels.

Whalen, M., and Coburn, T., July 1997, Perspectives on AFVs: 1996 Federal Fleet Manager Survey, NREL/TP-540-22720, Golden, CO: National Renewable Energy Laboratory. 


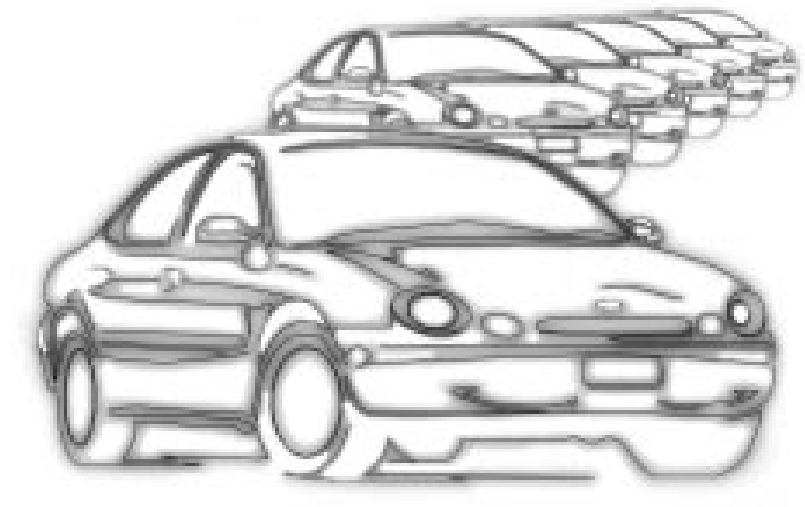

\section{Appendix A:}

Results Summarized by $C$ ensus Region

(State Responses) and by City Type

(C ity Responses)

Table A-1. N umber of responses by state fleet managers by census region and primary AFV type

\begin{tabular}{|c|c|c|c|c|c|c|c|c|}
\hline \multirow{2}{*}{$\begin{array}{c}\text { Census } \\
\text { Region }\end{array}$} & \multicolumn{10}{c|}{ Primary AFV Type } \\
Northeast & 14 & 3 & 3 & 0 & 4 & M85 & PROPANE & TOTAL \\
Midwest & 16 & 0 & 0 & 58 & 0 & 0 & 6 & 46 \\
South & 36 & 1 & 8 & 10 & 6 & 1 & 34 & 96 \\
West & 30 & 4 & 3 & 6 & 4 & 8 & 23 & 78 \\
\hline
\end{tabular}

Table A-2. N umber of responses by city fleet managers by city type (Clean Cities participants and other cities)

\begin{tabular}{|c|c|c|c|c|c|c|c|c|}
\hline & \multicolumn{1}{c|}{ Primary AFV Type } \\
\cline { 2 - 10 } City Type & CNG-CON & CNG-DED & CNG-BI & E85 & ELEC & M85 & PROPANE & TOTAL \\
Clean Cities & 85 & 8 & 7 & 6 & 9 & 8 & 25 & 148 \\
Other Cities & 77 & 7 & 5 & 14 & 6 & 2 & 28 & 139 \\
\hline
\end{tabular}

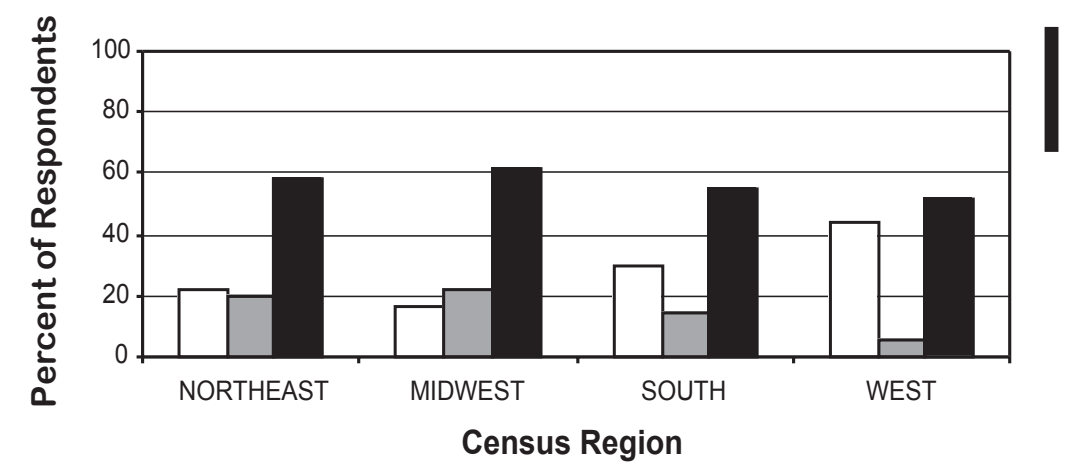

Figure A-1. State fleet manager

responses to "how acceptable are AFVs

to drivers?" by census region

$\square$ Don't want $\square$ Want $\quad \square$ No preference

Figure A-2. City fleet manager responses to "how acceptable are AFVs to drivers?" by city type

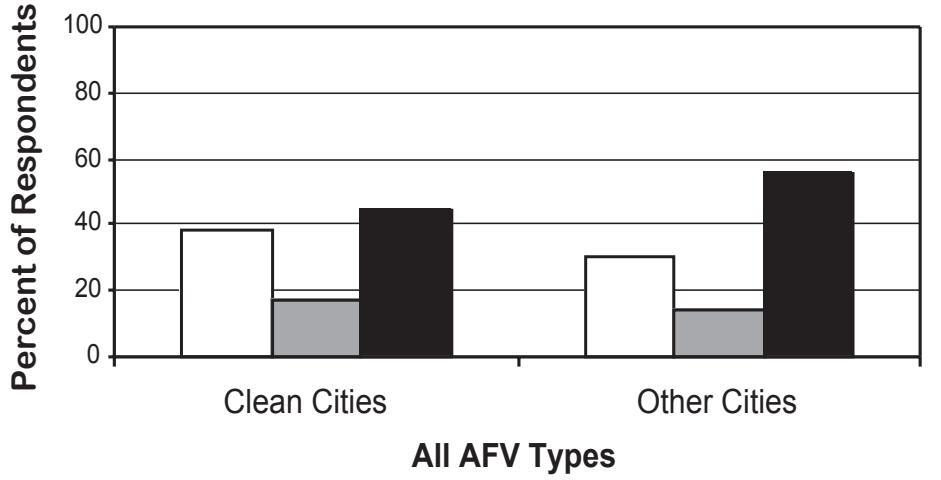

口Don't want $\quad \square$ Want $\quad \square$ No preference 


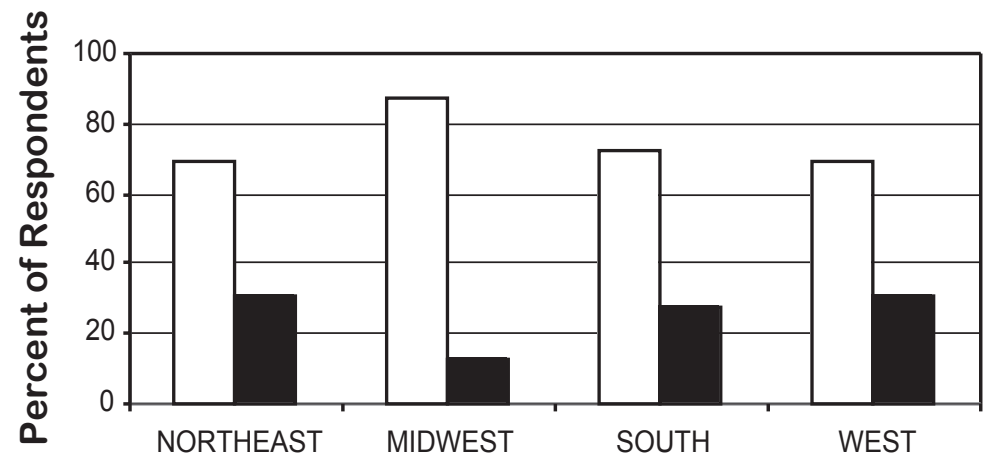

U.S. Census Region

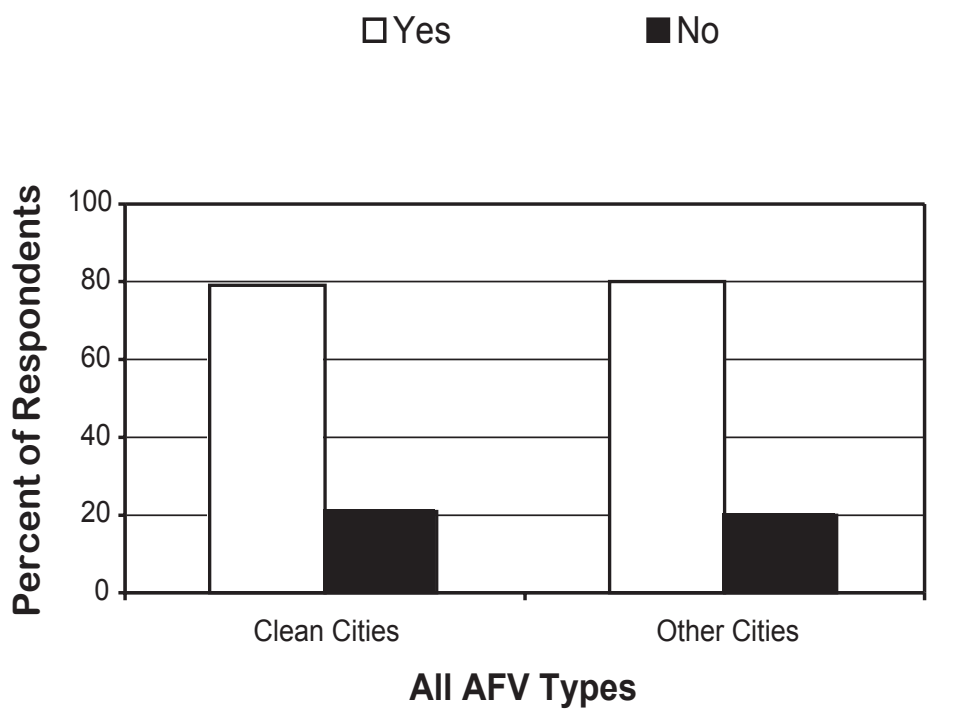

$\square$ Yes $\quad$ No
Figure A-3. State fleet manager responses to "is there an alternative fuel station nearby?" by census region

Figure A-4. City fleet manager responses to "is there an alternative fuel station nearby?" by city type
Figure A-5. State fleet manager responses on type of refueling station used by fleet by census region

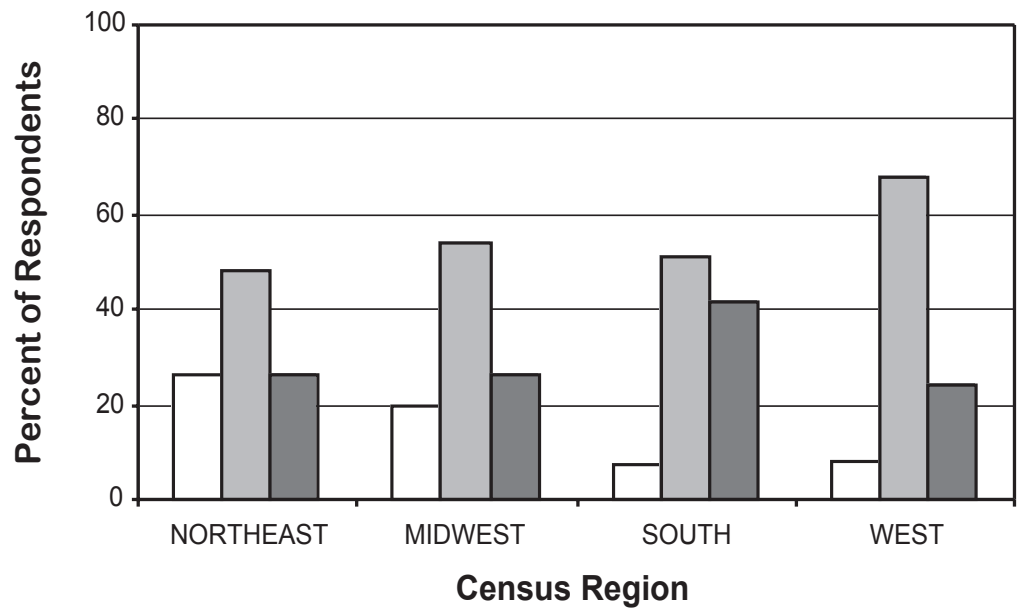

口On-site station $\quad \square$ Public station $\quad$ Local private station 
Figure A-7. State fleet manager responses to "what fuel are your AFVs usually operated on?" by census region

Figure A-8. City fleet manager responses to "what fuel are your AFVs usually operated on?" by city type

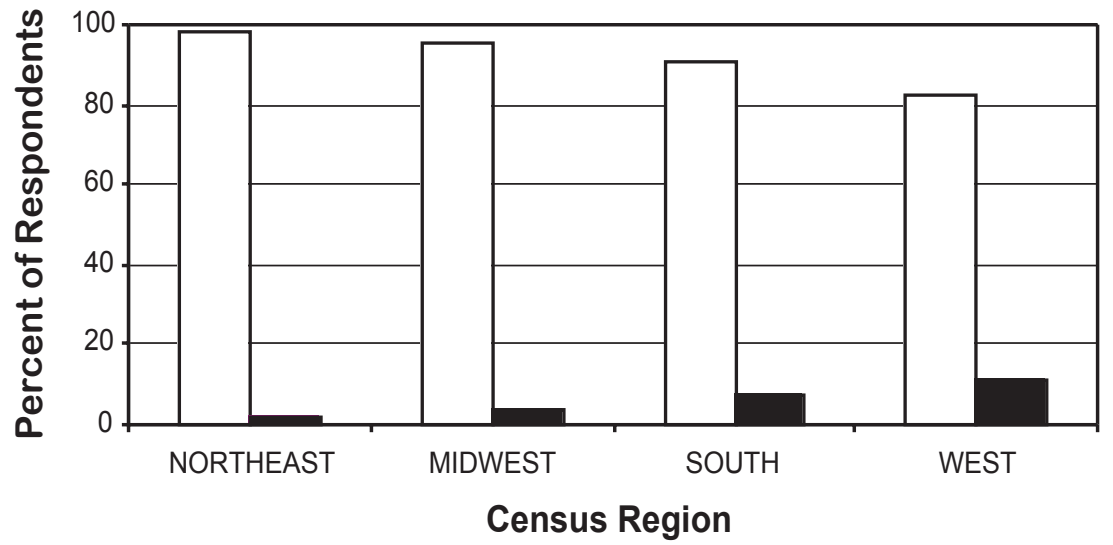

$\square$ mostly use alternative fuel $\square$ mostly use gasoline

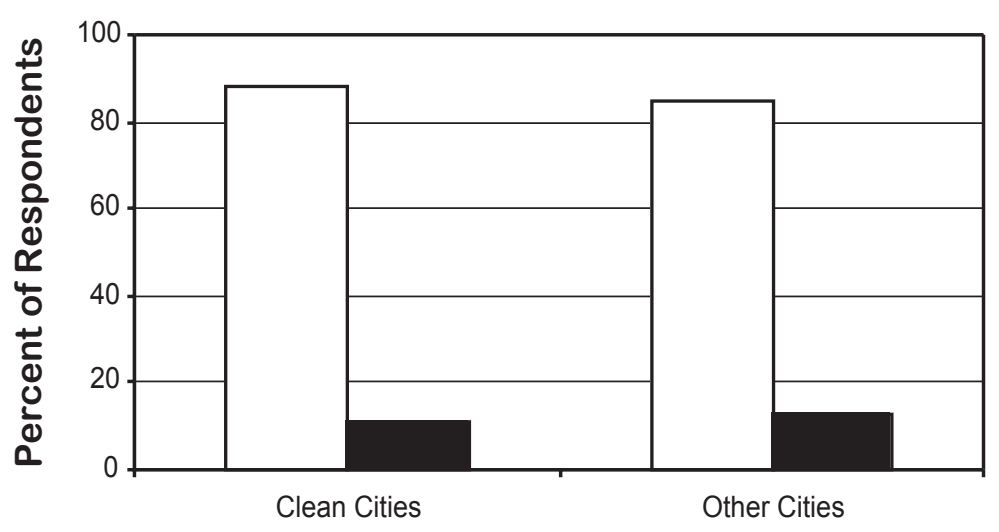

All AFV Types

$\square$ mostly use alternative fuel $\square$ mostly use gasoline

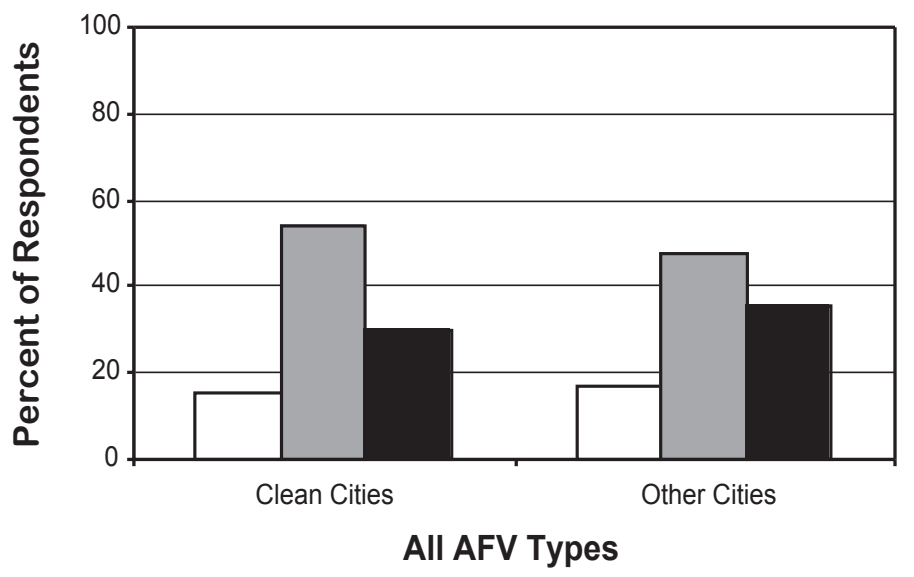

$\square$ On-site station $\square$ Public station
Figure A-6. City fleet manager

responses on type of refueling station

used by fleet by city type 


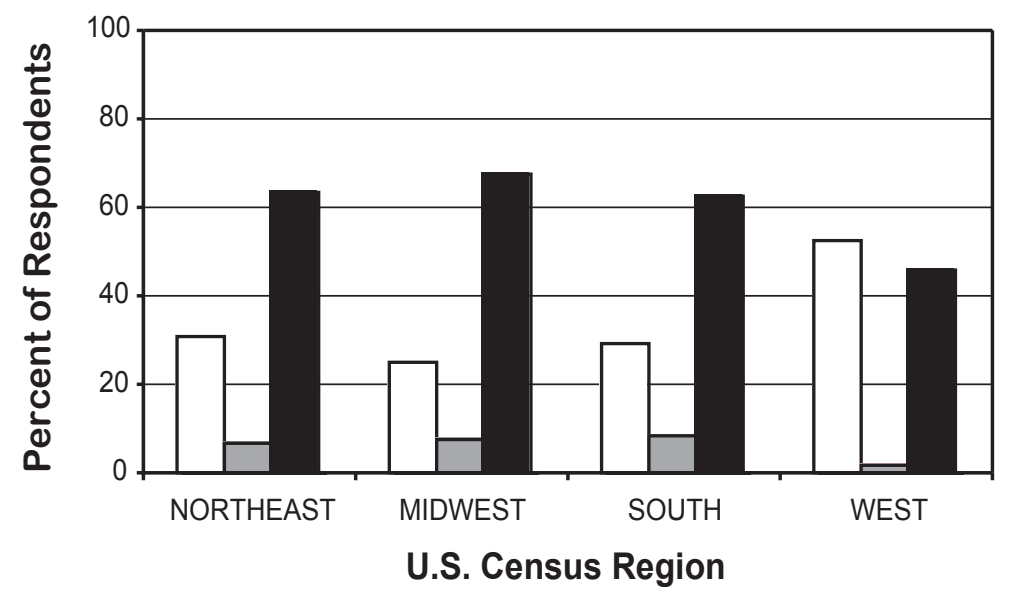

口more about AFVs amore about gasoline vehicles

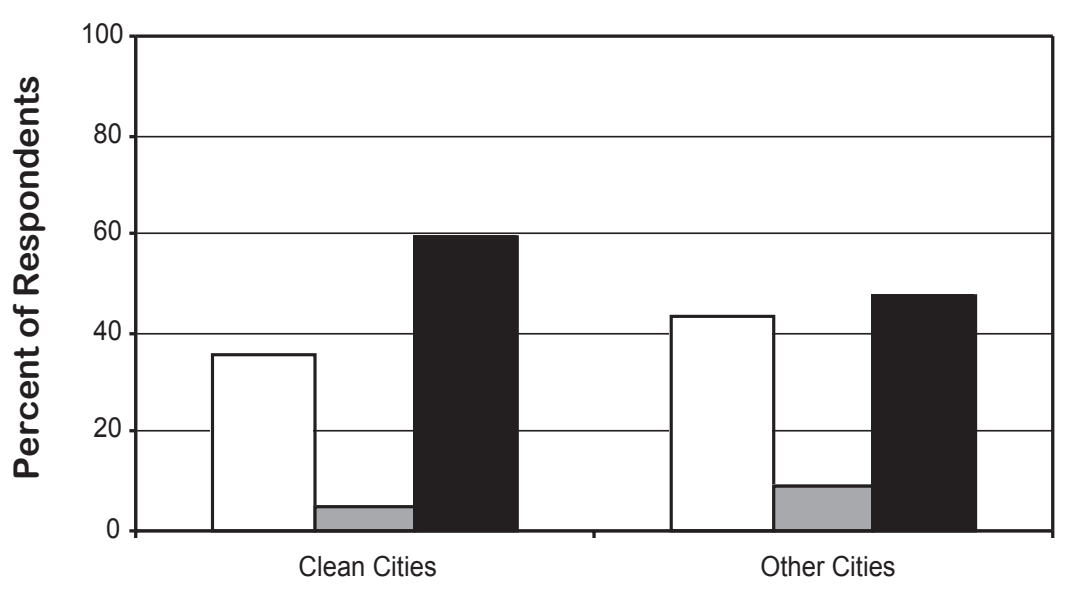

All Responses
Figure A-9. State fleet manager responses to "which vehicle type do you receive more complaints about?" by census region

Figure A-10. City fleet manager responses to "which vehicle type do you receive more compaints about?" by city type

\section{$\square$ more about AFVs $\square$ more about gasoline vehicles $\quad$ equal number}

Figure A-11. State fleet manager responses to "do your AFVs require more or different scheduled maintenance than similar gasoline vehicles?" by census region

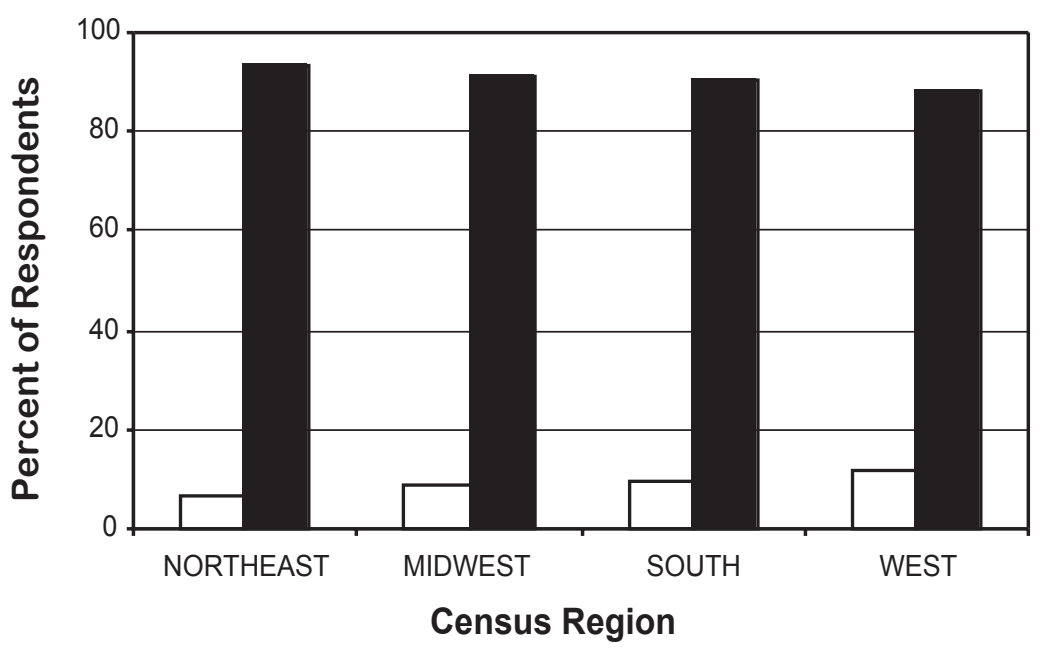

$\square$ Yes $\quad \square$ No 
State and City Government Fleet Manager Survey

Figure A-13. State fleet manager responses to "do your AFVs require more or different unscheduled maintenance than similar gasoline vehicles?" by census region

Figure A-14. City fleet manager responses to "do your AFVs require more or different unscheduled maintenance than similar gasoline vehicles?" by city type

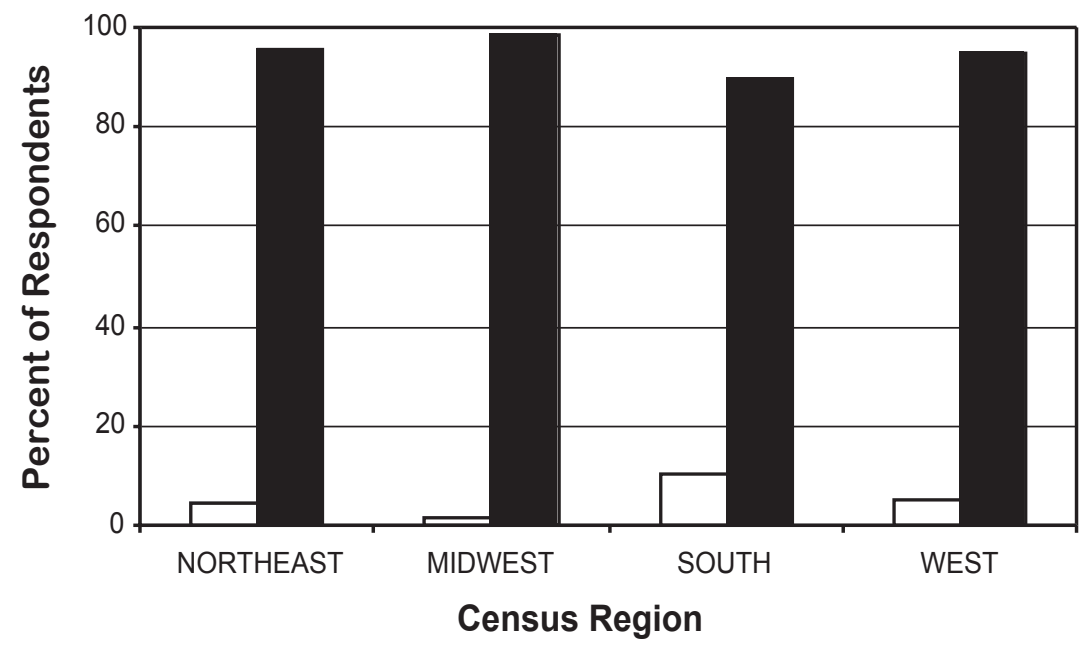

aYes $\quad$ No

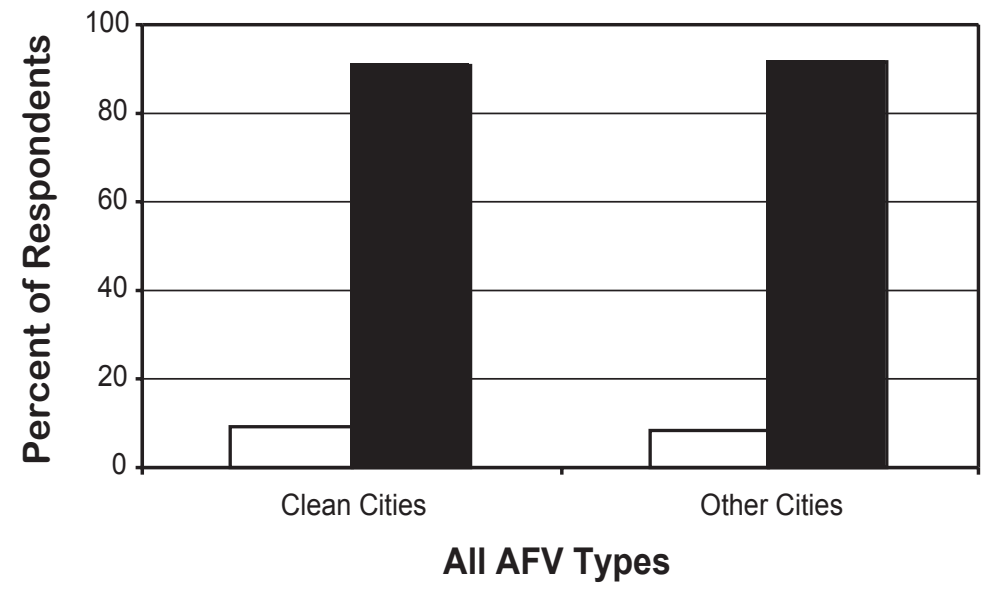

पYes $\quad$ No

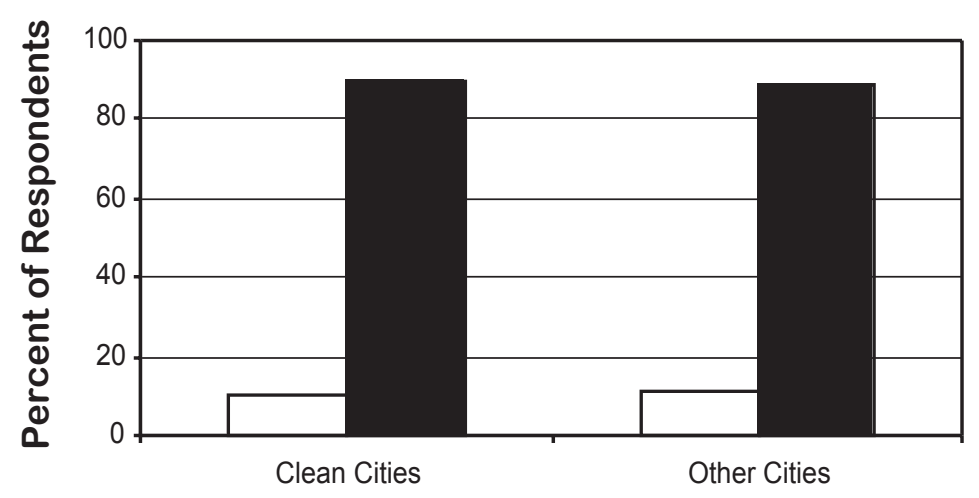

All AFV Types
Figure A-12. City fleet manager responses to "do your AFVs require more or different scheduled maintenance than similar gasoline vehicles?" by city type 


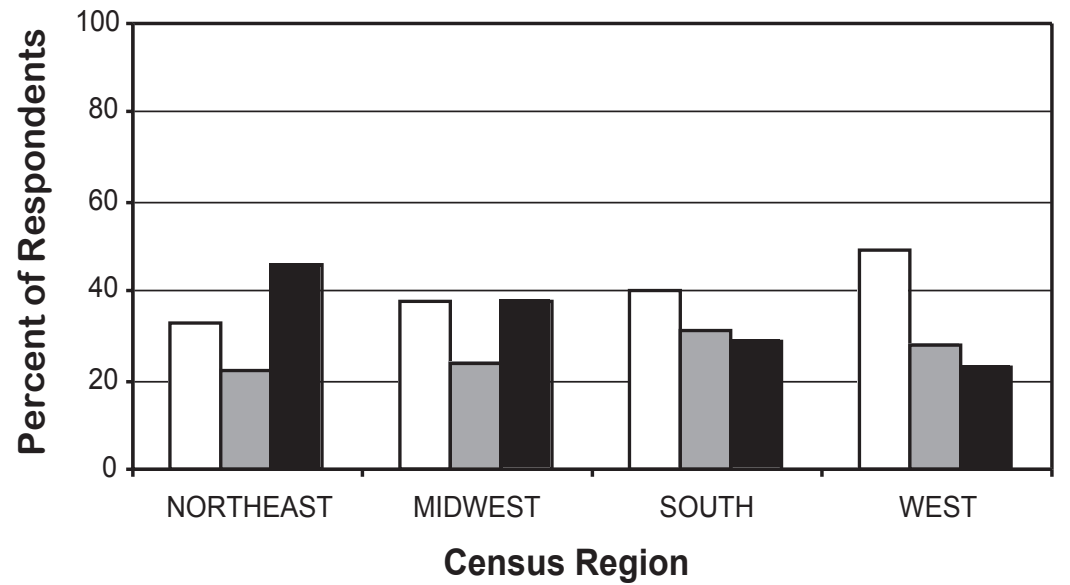

$\square$ AFVs cost more than gasoline vehicles

$\square A F V$ s cost less than gasoline vehicles

AFVs cost about the same as gasoline vehicles

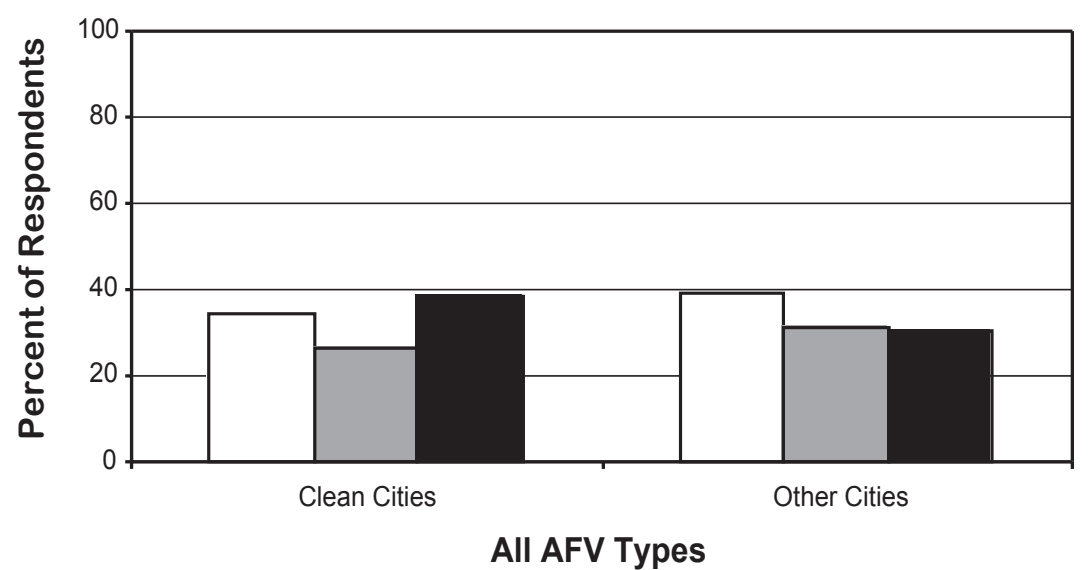

$\square \mathrm{AFV}$ s cost more than gasoline vehicles

$\square$ AFVs cost less than gasoline vehicles

- AFVs cost about the same as gasoline vehicles
Figure A-15. State fleet manager responses to "how do the costs of owning and operating AFVs compare to those of similar gasoline vehicles?" by census region
Figure A-16. City fleet manager responses

to "how do the costs of owning and operating AFVs compare to those of similar gasoline vehicles?" by city type 
State and City Government Fleet Manager Survey

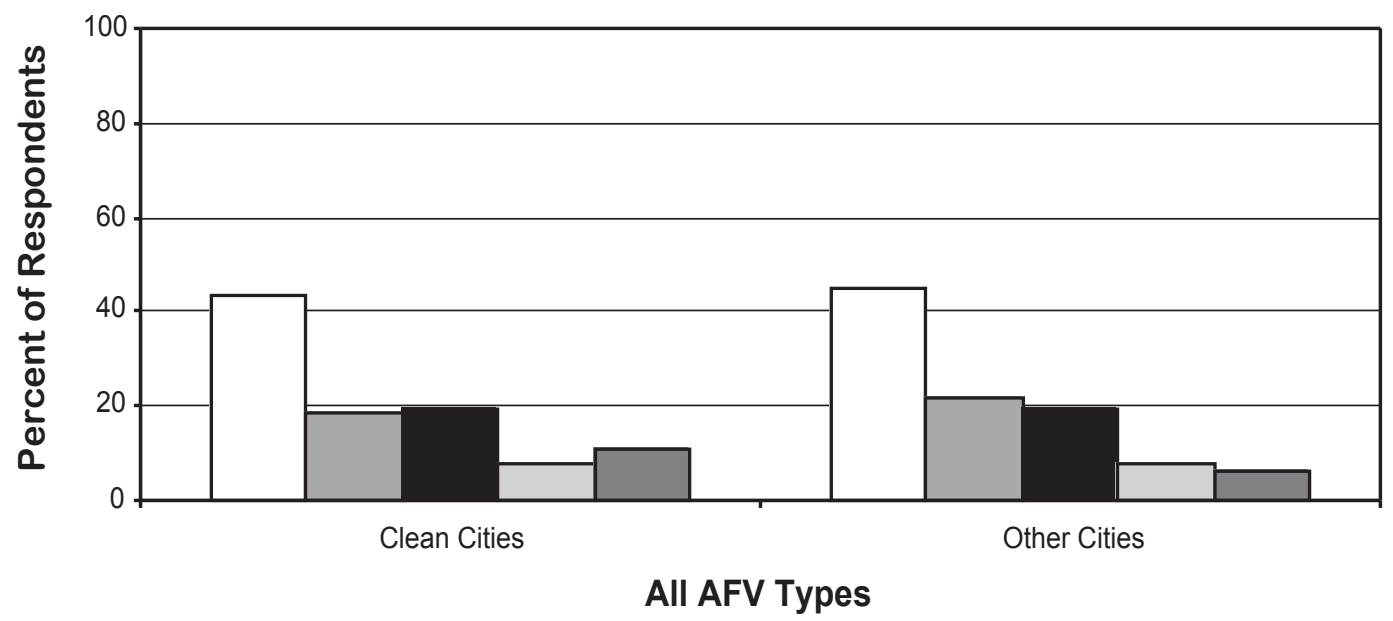

$\square$ very satisfied $\square$ leaning toward satisfied $\square$ neutral $\square$ leaning toward dissatisfied $\square$ dissatisfied

Figure A-17. City fleet manager responses about overall satisfaction with AFVs in fleet by city type 
Produced for the U.S. D epartment of Energy by:

\section{NREL}

1617 Cole Boulevard

Golden, Colorado 80401-3393

D O E N ational A Iternative Fuels H otline: 1-800-423-1D O E

W orld W ide W eb: http://www.afdc.doe.gov

February 1999

N REL/TP-540-23980 